\section{Research Square}

Preprints are preliminary reports that have not undergone peer review.

They should not be considered conclusive, used to inform clinical practice, or referenced by the media as validated information.

\title{
Skin Targeting of An Optimized Caffeine Nanostructured Lipid Carrier With Improved Efficiency Against Chemotherapy Induced Alopecia
}

\author{
Amna Makky \\ Cairo university \\ Eman Sadddar \\ Helwan university \\ Doaa galaa \\ egyptian drug authority \\ Abeer Khattab ( $\sim$ abeer_khattab75@yahoo.com ) \\ Egyptian Drug Authority
}

\section{Research Article}

Keywords: Caffeine, Topical, Alopecia, Nanostructured lipid carriers (NLCs)

Posted Date: November 11th, 2021

DOI: https://doi.org/10.21203/rs.3.rs-883972/v1

License: (a) This work is licensed under a Creative Commons Attribution 4.0 International License. Read Full License 


\section{Abstract}

The current investigation was designed to develop and optimize caffeine-loaded nanostructured lipid carriers (NLCs) for topical alopecia treatment. Screening of drug solubility in various excipients was executed. The $2^{3}$ full factorial design was employed for NLCs optimization. Lipid type, surfactant type, and drug concentration were the independent variables. Entrapment efficiency (EE), particle size, polydispersity index (PDI) and \% drug release were the chosen responses. Physiochemical evaluation, in vitro release, ex-vivo permeation, and stability study were achieved. The solubility of caffeine in stearic acid and glyceryl monostearate (GMS) was $47.11 \pm 3.048$ and $32.67 \pm 2.955 \mathrm{mg} / \mathrm{g}$, respectively. Oleic acid: garlic oil mixture at ratio $1: 1 \mathrm{v} / \mathrm{v}$ was the oily phase. Tween 80 and Cremophor EL, Transcutol HP, carbonate buffer (pH 10.8 and ionic strength $200 \mathrm{Mm}$ ) were chosen as a surfactant, co-surfactant, and aqueous phase, respectively. The optimized formula showed particle size, \%EE, PDI, zeta potential of $358 \mathrm{~nm}, 72.55 \%, 0.912,-24.8$, respectively. The \% release was $92.9 \pm 4.9 \%$ after 4 hours. Confocal laser scanning microscopy showed an improved permeation of caffeine-loaded NLCs to the whole skin layers. The histological examination proved the efficiency of caffeine NLCs optimized formula on promoting hair growth compared to the market formula.

\section{Introduction}

Dermatological route for drug administration offers a wide and easy application through self-administration and sought to be a substitute for oral drug delivery or hypodermic injection. Topical application of therapy ensures persistent contact for medical treatment in case of skin diseases or for transdermal drug absorption into the systemic circulation. Recently, topical drug delivery has shown significant benefits for drug targeting to the desired site. The topical administration of drugs reduces the systemic side effects and is also able to attain controlled drug delivery [1].

Stratum corneum (SC), one of the distinct skin layers, is an obvious hindrance for the application of topical formulations. Hydrophilic drugs transfer faces severe difficulty because of the stratum corneum high lipids and low water ratios (8:2), while lipophilic one's transfer is achieved by their solubilization within intercellular lipids around SC cells. Topical drug absorption is significant for transdermal drug delivery systems to maintain systemic and uniform therapeutic levels of the drug during the intended period of use. Hydrophilic drugs absorption can arise through dermal hair follicles and sebaceous glands pores [2].

Insufficient drug delivery and unfavorable skin interactions are the most recognized drawbacks of topical delivery which consequently led to patient noncompliance. So, the expansion of novel approaches that could overcome these drawbacks is of great importance. These novel systems are different from the conventional ones in their structures (internal and external matrix). Different classes of nano-carriers such as solid lipid nanoparticles (SLNs), liposomes, transfersomes, NLCs, micro and nanoemulsion, niosomes, dendrimers, and invasomes were developed for topical applications [3]. They are formulated for the efficacious delivery of bioactive agents with unlike physical characters through the skin. Improving drug transport and contact time through the skin, controlling drug release, enhancing the dissolution rate, protecting drugs against environmental changes, increasing skin hydration and drug penetration are some of lipid-based nanocarriers advantages [4].

NLCs present a dual combination core of solid and liquid lipid. Earlier researches discussed the effect of NLCs on increasing the amount of the drug retained in the pig ear skin. The inflammation intensity presented as serum cytokines level was obviously decreased upon using drug-loaded NLCs in psoriatic mice model [5].

Alopecia areata (AA) is an idiopathic skin disease that may greatly influence individuals or their social aspects of quality of life. Stress, autoimmune and genetic susceptibility are the most remarkable causes of AA. Targeted follicular drug delivery could improve the efficiency of existing medications to treat follicular origin diseases such as AA [6].

Caffeine is one of the commonly described drugs for hair follicle targeting. Caffeine or trimethylxanthine, is an alkaloid that acts as an adenosine receptor antagonist with anti-inflammatory and psychotropic actions. It is a weakly basic drug that has a high water solubility of $20 \mathrm{mg} / \mathrm{ml}$, pKa of 10.4, and logP of -0.07(a hydrophilic model drug with poor skin permeability) [7]. Caffeine has been revealed valuable effects on androgenic alopecia due to its influence on hair growth stimulating and hair loss prevention. Dihydrotestosterone (DHT) is the fundamental cause of hair loss in androgenic alopecia. It limits the anagen and telogen phases of the hair growth cycle, consequently, the follicles stay ungrowing and hair loss occurs. Caffeine acts by inhibition of 5-a-reductase, an enzyme that converts testosterone to DHT. In addition, it acts as a phosphodiesterase inhibitor; an enzyme that degenerates cAMP consequently, increasing cAMP levels in cells, counteracting the effects of the DHT hormone, and therefore promote hair growth. Moreover, caffeine increases blood supply to the follicles that promote hair growth. The recommended effective anti-hair loss dose of caffeine ranged from $0.001-0.005 \%$ [8].

This article was aimed to develop NLCs as potential carriers to improve the delivery of caffeine via the skin. The study was divided into two phases. Phase I, include pre-formulation studies for screening and identify the excipients, which would be suitable for drug formulation into lipid-based formulations (NLCs). Excipients such as stearic acid and GMS (solid lipid), surfactants (Tween 80 and Cremophore EL), and co-surfactants (Transcutol HP), and oils (e.g. IPM, amla oil, garlic oil, and oleic acid) were investigated to choose the optimum lipid carriers related to the physicochemical characters of the drug. Lipid solubility, surfactant type, surfactant/co-surfactant ratio, oil/surfactant ratio, and solid/liquid lipid miscibility are important formulation-related parameters. Phase II; include drug formulation into NLCs and the efficiency of formulation variables such 
as particle size, \%EE, in-vitro drug release, and drug permeation through the skin were judged through the independent variables for NLCs loaded caffeine.

\section{Materials And Methods}

\section{Materials}

Caffeine anhydrous was obtained as a gift from Pharmaceutical Egyptian Company, Cairo, Egypt. Span 20, Span 80, Tween 80, rosemary oil, garlic oil, oleic acid, methanol (HPLC grade), and formaldehyde were bought from (El-Nasr Pharmaceutical Chemical Company, Cairo, Egypt). Labrafil M1944, Transcutol HP, and Caproyl 90 were obtained from (Gattefosse, Cedex, France). Jojoba oil, Cremophor EL, hematoxylin, isopropyl myristate (IPM), eosin, xylene, Rhodamine B (RB), and paraffin beeswax were bought from Sigma-Aldrich Chemical Company, Cairo, Egypt. Caprylic/capric triglyceride, stearic acid, and GMS were bought from Pharmaceutical Egyptian Company, Cairo, Egypt. Amla oil was obtained from (Dabur Egypt limited company, Cairo, Egypt). Dipotassium hydrogen phosphate, potassium bromide (IR grade), and potassium dihydrogen phosphate were gotten from El-Gomhouria Company, Cairo, Egypt. Cellulose membrane was obtained from Sigma-Aldrich, Cairo, Egypt. ANOVA test "SPSS version 17.0 for Windows" (SPSS Inc., USA). Commercial (Market) lotion of caffeine (Dr. Wolff Plantur 39 Phyto caffeine tonic); Batch No. C60341 (Dr. Kurt Wolff, Bielefeld, Germany).

\section{Pre-formulation studies and excipients screening}

\section{Solubility studies}

Solubility of caffeine was estimated in distinct liquid lipids, namely; oleic acid, labrafil M1944, IPM, caproyl 90, amla oil, rosemary oil, garlic oil, caprylic/capric triglyceride, and jojoba oil or oil mixtures; oleic acid: garlic oil (O: G) at ratios (2:1, 1:2 and 1:1\% W/w). The solubility in surfactants (Tween 80 and Cremophor EL) and co-surfactants (Transcutol HP, Span 80, and Span 20) was also evaluated. An excess amount of caffeine (150mg) was dissolved in $1 \mathrm{gm}$ of each mentioned vehicle put into small stoppered vials. The drug-vehicle mixtures were constantly shaken for $72 \mathrm{~h}$ at $37^{\circ} \mathrm{C} \pm 1.0^{\circ} \mathrm{C}$ in a mechanical shaker (Shaking water bath, B S-11, Isothermal shaker, Korea). After equilibrium, the samples were centrifuged at $3000 \mathrm{rpm}$ for $20 \mathrm{~min}$. The supernatant was diluted with methanol and filtered through a $0.45 \mu \mathrm{m}$ membrane filter [9].

Caffeine concentration was measured by the HPLC-UV method after drug separation through Zorbax Eclipse Plus column C18 (150 mm x $4.6 \mathrm{~mm}, 5$ $\mu \mathrm{m}$ particle size). The column temperature was kept at $40^{\circ} \mathrm{C}$. The mobile phase consists of (water: methanol at ratio $60: 40 \% \mathrm{v} / \mathrm{v}$ ). An injection volume of $20 \mu \mathrm{l}$, a flow rate of $1 \mathrm{ml} / \mathrm{min}$, and a wavelength of $275 \mathrm{~nm}$ were adopted [10]. Caffeine solubility in distinct solid lipids namely, stearic acid and glyceryl monostearate (GMS) were also performed. One gram of each lipid was firstly melted at $80^{\circ} \mathrm{C}$ in a $10 \mathrm{ml}$ stoppered tube. The drug was gradually added to the melted lipid by increasing $5 \mathrm{mg}$ per time then allowed to stir at $100 \mathrm{rpm}$ via (digital hot plate magnetic stirring, Jenway, 1000 , UK.) until the melted lipid failed to dissolve any more drug. Drug solubility in the molten lipid was judged optically within $15 \mathrm{~min}$ by noticing the absence or presence of drug crystals. The experiment was conducted in triplicate [11].

\section{Screening of lipids miscibility and drug solubility}

From the previous solubility studies, the liquid and solid lipids that showed the highest solubility of caffeine were chosen for the miscibility screening test. Stearic acid or GMS and O: G at ratio (1:1) were blended at ratios; 50:50, 60:40, 70:30, 80:20 and 90:10. Each mixture was agitated at 200 rpm and $85^{\circ} \mathrm{C}$ for $1 \mathrm{hr}$ in a water bath shaker (B S-11, Isothermal shaker, Korea) and then allowed to cool at room temperature for solidification. The miscibility of liquid/solid lipid mixture was examined by placing a smear of the cooled solid mixture on a filter paper. The existence or loss of oil droplets on the filter paper was observed. The absence of oil droplets will be judged as a homogenous miscible mixture. The liquid/solid lipid mixture that showed good miscibility was estimated for caffeine solubility using the above-described method for solid lipid [12].

\section{Screening the optimum aqueous phase for preparation NLCs}

Phosphate buffer at pHs 7.4 and 7.8 and carbonate buffer at $\mathrm{pH} 10.8$ at different ionic strengths were evaluated for drug solubility. Both phosphate buffer at $\mathrm{pH} 7.4$ and 7.8 , and carbonate buffer at $\mathrm{pH} 10.8$ with ionic strength $(50,100,150$, and $200 \mathrm{mM})$ were prepared. The equilibrium solubility values of caffeine in aqueous and organic phases were measured by the classical saturation shake-flask method in duplicate [13].

Firstly, a saturation state for both solvents was done. An aliquot of $25 \mathrm{ml}$ of aqueous phase (buffer system) was added to $25 \mathrm{ml}$ of $\mathrm{n}$-octanol in a separating flask and allowed to be shaken in a mechanical shaker for $24 \mathrm{~h}$. The solvents were allowed to stand enough time for phase separation and used for checking the drug solubility. Partitioning of caffeine between the two phases (organic and aqueous) is carried out by transferring an accurate amount of the drug $(20 \mathrm{mg})$ into a stoppered separating funnel containing equal volumes of both phases. The funnels were subjected to constant shaking at $25^{\circ} \mathrm{C}$ for $3 \mathrm{hr}$ then allowed to stand with rotation from time to time through $180^{\circ}$ about its transverse axis to allow enclosed air to rise through the two phases and such rotations were sufficient to create partition equilibrium separation. The drug concentration in all buffer systems with their different ionic strength was determined according to the above-mentioned HPLC method. The buffer system showing the lowest drug solubility will be chosen as an optimum solvent for the formulation of caffeine-loaded NLCs.

\section{Optimization of caffeine-NLCs}


NLCs dispersions were firstly diluted (1:10) with distilled water and $\mathrm{pH}$ was measured (pH meter, HANNA instrument, USA). The pH of each dispersion was measured three times at ambient temperature. The electrical conductivity $(\sigma)$ of the NLCs dispersions was determined using (HANNA digital conductometer instrument, USA) at a constant frequency of $1 \mathrm{~Hz}$ at ambient temperature. The average reading \pm S.D of triplicate measurements was recorded.

\section{Determination of particle size, PDI, and zeta potential}

The particle size, polydispersity index (PDI), and zeta potential of caffeine loaded NLCs were determined by (Malvern Zetasizer nano series, Nano ZS 3000, Malvern, U.K) with a 50 MV laser. An amount of $1 \mathrm{gm}$ from each formula was dispersed in $100 \mathrm{ml}$ of distilled water under constant shaking. An aliquot of $1 \mathrm{ml}$ of this suspension was put into the cell for particle size and PDI analysis which was carried out at a fixed angle of $90^{\circ}$ and temperature of $25^{\circ} \mathrm{C}$. For zeta potential analysis, the diluted samples were exposed to an electric field (1V). The data were expressed in triplicate \pm S.D [18].

\section{In-vitro release study}

Caffeine release from NLCs was performed using cellulose membrane (Sigma, molecular weight cut off is ranged from 12,000-14.000 Da) pre-soaked overnight at $25^{\circ} \mathrm{C}$ in phosphate buffer $\mathrm{pH} 7.4$. One milliliter of each formula was put in a glass tube of $2.5 \mathrm{~cm}$ diameter and $6 \mathrm{~cm}$ length. One end was tightly sealed with the dialysis membrane and the other end was hanged to the shaft of the dissolution apparatus (Hanson dissolution apparatus I, USA). The tubes were put into phosphate buffer solution $(100 \mathrm{ml})$, which was constantly stirred at $100 \mathrm{rpm}$ and about $37^{\circ} \mathrm{C}$. Two-milliliter aliquots of release medium were taken at different intervals $(15,30,45,60,120 \mathrm{~min}$.) and substituted by a fresh buffer solution [19]. The aliquots were analyzed for the determination of drug concentration using the HPLC method previously described at $275 \mathrm{~nm}$. Analysis was run in triplicate and the mean value \pm S.D was calculated.

\section{Ex-vivo permeation and skin retention study}

This test was performed for the formulas which exhibited a high percentage release compared to the market formula. This test was done as mentioned in the in vitro release test with the exception of using excised neonate rat skin instead of cellulose membrane. Aliquots of $2 \mathrm{ml}$ were taken from receptor partition at time intervals $(0.5,1,2,4,6,8,10,12,24 \mathrm{hr})$ and substituted with the same volume of fresh buffer. The withdrawn samples were filtered through $0.22 \mu \mathrm{m}$ filters and analyzed for drug concentration using the HPLC method mentioned above.

The cumulative amounts of caffeine permeated throughout the skin per unit surface area (Eq.4) were plotted against time to construct the drug permeation profiles.

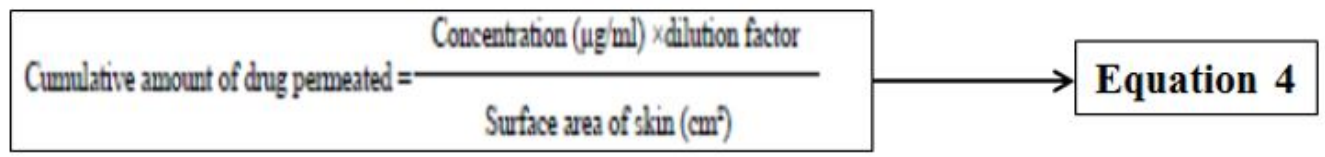

At the end of the experiment (after 24hr), the skin was dehydrated with cotton and washed several times with distilled water then cut into small pieces $\left(2 \times 2 \mathrm{~cm}^{2}\right)$. These pieces were dipped into methanol $(25 \mathrm{ml})$ for caffeine extraction then subjected to ultrasonication for 30 minutes at $40^{\circ} \mathrm{C}$, vortexed for 3 minutes, filtered through $0.22 \mu \mathrm{m}$, and analyzed for drug concentration using HPLC [9].

\section{Permeation data analysis}

The cumulative amount of caffeine permeated through the rat skin $\left(\mathrm{Q}, \mu \mathrm{g} / \mathrm{cm}^{2}\right)$ was plotted as a function of time (t, hr) for each formula. The permeation rate at the steady-state (flux) (Jss, $\left.\mu \mathrm{g} / \mathrm{cm}^{2} / \mathrm{h}\right)$ and time were calculated from the slope and the intercept of the straight line obtained by plotting the cumulative amount permeated per unit area of skin versus time at steady-state condition, respectively. Permeability coefficient (Kp) was calculated by dividing the flux by initial drug concentration (Co) in the donor portion of the cell following the equation below [9]:

$\mathrm{Kp}=\mathrm{J}_{\mathrm{ss}} / \mathrm{Co}$

Enhancement ration $(\mathrm{Er})$ was calculated by dividing the $\mathrm{Jss}$ of the respective formula by the $\mathrm{J}_{\mathrm{ss}}$ of the market formula as given below:

$\mathrm{Er}=\mathrm{J}_{\mathrm{sS}}$ of formulation/Jss of control

\section{Statistical analysis}

The in-vitro release, ex-vivo permeation and skin retention data expressed as mean \pm standard deviation were statistically analyzed by utilizing the principles of one way ANOVA test "SPSS version 17.0 for Windows" (SPSS Inc., USA) followed by post HOC Duncan alpha (0.05)(95\% confidence interval).

\section{Transmission electron microscopy (TEM)}


Morphology of the optimized caffeine-NLC formula was inspected by TEM (Tecnai G20, Super twin, double tilt, FEl, Netherland) after dilution at ratio $(1: 10 \% \mathrm{w} / \mathrm{v})$ with double distilled water. One drop of the diluted sample was put onto a copper grid (200-mesh), negatively stained with $1 \%$ phosphotungstic acid, and then dried on the carbon-coated grid. After four minutes, a filter paper was used to eliminate extra liquid droplets at the copper grid edge. The sample was dried at $25^{\circ} \mathrm{C}$ and then observed by TEM [20].

\section{Stability studies for the optimized formula as per ICH guidelines}

Stability studies of the optimized caffeine-loaded NLC formula were accomplished according to ICH Q1A (R2) guidelines. The optimized formula was kept at temperature; $25 \pm 2{ }^{\circ} \mathrm{C} /$ relative humidity; $65 \% \pm 5 \%$ for 12 months. The stored formula was periodically analyzed for pH, particle size, PDI, entrapment efficiency, zeta potential, phase separation, color, and clog formation [21].

\section{In-vivo studies}

The animal protocol was carried out according to the experimental protocol was approved by the Animal Care Ethics Committee, Faculty of Pharmacy, Cairo University No (88) for 31/12/2018.

\section{Confocal laser scanning microscopy (CLSM)}

Rhodamine B (RB); a commonly fluorescent dye at a concentration $(5 \mu \mathrm{g} / \mathrm{ml})$, was loaded with caffeine NLC optimum formula. Experimental rats were split into two groups (each containing 3 rats at least). Group 1 was treated with caffeine NLC optimum formula, group 2 was treated with caffeine aqueous solution loaded with RB (control). Animals in different groups were provided the amount of drug equivalent to $15 \mathrm{mg}$ of caffeine. The drug application was occurred by rubbing on the dorsal side of rat skin at the square area $\left(4 \times 3 \mathrm{~cm}^{2}\right)$ twice per day for $48 \mathrm{~h}$. The rats were anesthetized and sacrificed after drug administration for $48 \mathrm{~h}$. The rat skin was cleaned with a sponge and immersed in $1 \%$ paraformaldehyde solution for 30 min. Three perpendicular cuts $(10 \mu \mathrm{m})$ of each sample were gotten via slidge microtome, cleared in xylene, and embedded in paraffin at 56 degrees in a hot air oven for $24 \mathrm{~h}$. The obtained tissue sections were collected on glass slides, deparaffinized and the spreading of the dye was noticed using a confocal laser microscope. Skin pieces were inspected using normal and UV light (excitation at $405 \mathrm{~nm}, 458 \mathrm{~nm}, 488 \mathrm{~nm}, 514 \mathrm{~nm}, 543 \mathrm{~nm}$ ), and emission spectra were recorded at $633 \mathrm{~nm}$. The CLSM photographs in bright-field were overlaid to observe RB distribution [22].

\section{Hair growth evaluation}

Twelve to eighteen months-old female rats with an approximate weight of (200-250g), got from the animal house of The National Organization for Drug Control and Research, were used for in-vivo assessment of caffeine-loaded NLC as an anti-hair loss agent. The rats were subjected to nutritive adaptation, under well-ordered environmental conditions; temperature, $25 \pm 1{ }^{\circ} \mathrm{C}$; relative humidity, $45 \pm 5 \%$; and 12 -h light/ dark cycle) for 1 week prior to the experiment. Alopecia induction of rats was convinced by intraperitoneal (i.p) injection of a single dose of a chemotherapeutic agent of 1.5 $\mathrm{mg} / \mathrm{kg}$ etoposide once daily for 3 consecutive days [23]. The rats were divided into four groups, each contains 3 animals. A positive control (Group 1) was used, whereas animals were inducted with a chemotherapeutic agent and not received any treatment. Group two were treated with the market formula, group three were treated with optimized caffeine-loaded NLC formula and group four were treated with the blank formula of the optimized NLC. The animals in each group except group four were delivered topically an amount of the drug equivalent to $3 \mathrm{mg}$ twice/day for 30 days at a square area of $10 \times 5 \mathrm{~cm}$ of the dorsal part and rubbed 3-4 times. This process was repeated every morning and evening for 4 weeks. Rat's skin was observed for hair growth by taking photographs by using a D70 model camera (Nikon, Tokyo, Japan) after 1, 7, 14, 21, and 30 days of treatment [24].

\section{Histopathological analysis}

During the period of treatment, skin biopsies (pieces) were taken for histological examination on the $10^{\text {th }}$ and $20^{\text {th }}$ day of treatment after temporary anesthesia of the rats. On the $30^{\text {th }}$ day of treatment, the rats were sacrificed and skin specimens were also taken. These skin pieces were settled in $10 \%$ formalin solution for $24 \mathrm{hr}$, rinsed with water, and diluted several times with absolute, methyl, and ethyl alcohols for dehydration. They were purified in xylene and fixed in paraffin at 56 degrees in a hot air oven for $24 \mathrm{hr}$. Tissue paraffin blocks of $4 \mu \mathrm{m}$ thickness were obtained using slidge microtome. The tissue blocks were placed on glass slides, deparaffinized, stained by hematoxylin and eosin stains, and scanned by the light electric microscope for histopathological inspection [25].

\section{Results And Discussion}

\section{Solubility study}

Table 2 presents the findings of caffeine solubility in different types of lipid phases and surfactants. The solubility of caffeine in stearic acid and GMS (solid lipids) was $47.11 \pm 3.048,32.67 \pm 2.955 \mathrm{mg} / \mathrm{g}$, respectively. Solubility of caffeine in liquid oils showed high solubility in oleic acid $17.043 \pm$ $0.715 \mathrm{mg} / \mathrm{g}$ and lowest solubility in garlic oil $(0.15 \pm 0.022 \mathrm{mg} / \mathrm{g})$. The solubility of caffeine in oils was arranged in descending order as follow; oleic acid > caproyl 90 > 0: G (2:1) > Labrafil M1944 > jojoba oil > 0: G (1:1) > amla oil > rosemary oil > CCTG > 0: G (1:2) > (IPM) > garlic oil. The results also revealed that caproyl 90, O: G (2:1), Labrafil M1944, jojoba oil, and O: G (1:1) had an intermediate effect on the drug solubility that ranged from 6.37 to $4.07 \mathrm{mg} / \mathrm{g}$. 
Mixing garlic oil with oleic acid had a marked effect on reducing the drug solubility in the oil mixture. Increasing the ratio of garlic oil in the oil mixture obviously decreased the amount of drug dissolved. The solubility of caffeine in $0: \mathrm{G}(2: 1), \mathrm{O}: \mathrm{G}(1: 1)$ and $0: \mathrm{G}(1: 2)$ was $6.37 \pm 1.15,4.07 \pm 0.54$, and $0.89 \pm 0.093 \mathrm{mg} / \mathrm{g}$. These results were related to garlic oil nature that contains oil-soluble organosulfur components [26].

Hence, the extent of drug solubility in lipid excipients greatly affects the drug loading; it was expected to choose oleic acid for NLCs preparation. In this experimental part, the authors not only focused on the drug solubility, but also on how to maximize the therapeutic efficiency of the applied dosage form. This was accomplished through the drug used and the synergistic effect that could be achieved from vehicles having benefits in hair follicle targeting and hair growth-promoting for alopecia treatment [27]. Accordingly, oleic acid: garlic oil (0: G) mixture at ratio 1:1 v/v was picked as the liquid oil phase for NLCs preparation. Oleic acid acts as a skin permeation enhancer through interaction and modification of SC lipids, thus, forms a new type of lipid domain that can decrease the capacity of skin barrier function. Consequently, it will disorganize and increase the lipid packing fluidity, decrease the diffusional resistance, and facilitates permeation [28]. Garlic oil has different health-promoting benefits, especially its effect as antifungal, antimicrobial, and hair growth promoting properties [26].

The solubility of caffeine in Tween 80 and Cremophor EL was $8.87 \pm 0.49$ and $8.66 \pm 0.756 \mathrm{mg} / \mathrm{g}$, respectively (Table 2). Both surfactants exhibited similar HLB values which may explain the slight difference in their ability to solubilize the drug. Both are nonionic surfactants that are less toxic and used with low concentrations for effective reduction in interfacial tension. The solubility of caffeine in co-surfactant, Transcutol HP, Span 20 , and Span 80 , was $25.82 \pm 0.0832,14.2 \pm 0.448$, and $6.25 \pm 0.68 \mathrm{mg} / \mathrm{g}$, respectively (Table 2). The results revealed that Transcutol HP showed the highest solubilization capacity for caffeine and that was attributed to the more hydrophilic properties of Transcutol HP relative to Span 20 or Span 80. Transcutol HP was supposed to raise the interfacial fluidity of a surfactant's external surface in the micelles thus enhancing the solubilization and emulsification [29].

Upon comparing the solubility level of the drug in various estimated phases, co-surfactants, surfactant, solid and liquid lipid, it was found that the highest solubility of the drug was in the solid lipid (about twice or more drug solubility in liquid lipid or surfactant or cosurfactant). This result was the same informed by Amanda, et al., [30] who found that solubility of fluconazole (hydrophilic in nature) was the highest solubility in solid lipid reaching $250 \mathrm{mg} / \mathrm{g}$ stearic acid and reaches $45 \mathrm{mg} / \mathrm{g}$ castor oil.

\section{Miscibility of liquid and solid lipid, surfactant and co-surfactant, and drug solubility in mixtures}

The NLCs are modulated by the addition of liquid lipids to the solid lipids which make their difference from SLNs. The solid/liquid lipids mixture imparts imperfection or amorphous structures to NLCs matrices. NLCs lipid molecules generate large distances among fatty acid chains, more drug accommodation occurred, and thus increase drug loading during storage [31]. Accordingly, the miscibility test was carried out for determining the ratio of liquid: solid lipid that showed high miscibility and ensures high drug loading capacity. The solid lipid, stearic acid or GMS, and the liquid lipid, $\mathrm{O}$ : G at ratio 1:1, were blended at ratios; $90: 10,80: 20$. 70:30, 60:40 and 50:50. Results revealed that the blends at ratios 90:10, 80:20, and 70:30 showed very good miscibility, whereas, increase the ratio of liquid lipid in the blend as in the ratios 60: 40 and 50:50 showed clear oil droplets on the filter paper that ensure immiscibility of the two phases. These results previously reported that a liquid lipid content of $30 \% \mathrm{w} / \mathrm{w}$ or less was optimal, as higher oil concentrations resulted in the generation of immiscible mixtures and the possibility of nanostructuring of NLC decreases [32].

The solubility of caffeine in selected lipid blends containing stearic acid/0: $\mathrm{G}$ at ratio 1:1 at ratios 90:10, 80: 20, and 70: 30 was 25, 30 , and 35 mg/g, respectively, and was 25,30 , and $40 \mathrm{mg} / \mathrm{g}$, respectively, for lipid blends containing GMS as solid lipid. It was clear that drug solubility in the lipid blends increases with increasing liquid lipid ratio. The increase in the volume of liquid lipid decreases the melting point with keeping the solid-state of the solid lipid, decreases the viscosity of the mixture, and increases the dynamic equilibrium for drug molecules that in turn increases drug solubility and minimizes the drug escaping as well as gives better stability to the blend [33].

\section{Solubility study of the drug in different aqueous media}

This experimental part has potential importance for the preparation of water-soluble drugs as solid lipid nanocarriers, which was accepted to increase the percentage of drug-loaded into the NLCs and reduce the amount of drug escape to the aqueous medium. Solubility of caffeine in different buffer systems, pHs, and ionic strengths are presented in table 3 . The results showed that caffeine exhibited the lowest solubility in carbonate buffer at higher $\mathrm{pH} 10.8$ and ionic strength $200 \mathrm{mM}$ that reached $8.01 \%$.

Using phosphate buffer systems at pH 7.4 and 7.8 showed that increasing the $\mathrm{pH}$ had an obvious effect on decreasing the drug solubility, especially with increasing the ionic strength of the medium (Table 3). At ionic strength $50 \mathrm{mM}$, the drug solubility was nearly the same at both pHs, 4.565 and 4.541 at $\mathrm{pH} 7.4$ and 7.8 , respectively. Upon increasing the ionic strength of phosphate buffer (200mM), the drug solubility progressively decreased to reach 2.146 and 1.413 at $\mathrm{pH} 7.4$ and 7.8 , respectively. The same result was clearly observed with carbonate buffer at pH 10.8 , whereas the drug solubility decreased from $3.320 \%$ at $50 \mathrm{mM}$ ioinc strength to 0.801 at $200 \mathrm{mM}$.

The results revealed that increasing the buffer ionic strength statistically decreased the drug solubility, especially if it is accompanied by an increase in the $\mathrm{pH}$ of the buffer system. The lower solubility in buffers with high ionic strength was related to increasing the concentrations of dissolved ionic salts that in turn could decrease the solubility of the weak electrolytes. Moreover, these results could be due to weak basic properties of the drug that showed low solubility at high $\mathrm{pH}$ and high solubility at lower $\mathrm{pH}$. At acidic $\mathrm{pH}$, the drug has high solubility due to its ionization, whereas, at basic $\mathrm{pH}$ 
(carbonate buffer at $\mathrm{pH} 10.8$ ) the drug is in the un-ionized form, consequently the solubility decreased leading to precipitation in a crystalline or amorphous form [34]. These findings were similar to Mayer, et al. [35] who informed that altering the pH of the buffer system was the best choice for encapsulating doxorubicin (water-soluble drug) inside the liposomes. Accordingly, carbonate buffer at pH 10.8 with ionic strength $200 \mathrm{mM}$ was selected as the optimum aqueous medium for encapsulating caffeine into NLCs.

\section{Optimum excipients for caffeine-NLCs preparation}

Table 4; illustrates the composition of caffeine-NLCs formulas. The S/CoS mixture at ratio 3:1 was used at a fixed concentration of 3\% w/v. The lipid blends were used at a fixed concentration of $2 \% \mathrm{w} / \mathrm{v}$ whereas, the ratio of solid lipid: liquid lipid was $70: 30$ and drug concentration was 1.5 and $3 \%$ w/v. Carbonate buffer pH 10.8 at ionic strength $200 \mathrm{mM}$ was used as an aqueous phase for the emulsification process due to low drug solubility that is expected to increase the \%DL and \%EE. The formulas were characterized for DSC, FTIR, \%Yield, \%DL, \%EE, particle size, zeta-potential, PDI, pH, electroconductivity, in-vitro release, and ex-vivo permeation.

\section{Characterization of caffeine loaded NLCs}

\section{DSC}

Thermal analysis by DSC was used for detecting drug-excipient incompatibilities, melting point, and recrystallization performance of bulk lipids used in the formulation of caffeine loaded-NLCs [36]. Fig. 1 showed DSC thermograms of the components of caffeine-loaded NLC; (a) caffeine, (b) GMS, (c) stearic acid, (d) physical mix at ratio (1:1), (e) blank NLC, and (f) optimum NLC formula C3. Caffeine showed a sharp endothermic peak with a melting point of $235^{\circ} \mathrm{C}$ which was similar to that reported by Carmelo et al., [37], Fig. 1(a). DSC thermogram of GMS revealed a sharp endothermic peak at $56.59^{\circ} \mathrm{C}$ revealing its melting point (Fig.1(b)).

These findings agreed with that of Freitas and Müller, [38] who studied the DSC of GMS that exhibited an endotherm melting point around $60^{\circ} \mathrm{C}$. DSC profile of stearic acid showed an endothermic peak at $57.93^{\circ} \mathrm{C}$, Fig. 1(c) [39]. DSC thermogram of the physical mix, blank NLC, and optimum NLC formula for caffeine, (Fig. 1(d), 1(e), and 1(f) presented a broad endothermic peak at $300^{\circ} \mathrm{C}$, which revealed the absence of caffeine peak. It is known that when the drug endothermic peak does not appear in thermogram of nanopreparations or in the physical mixture, drug converted from crystalline to amorphous phase that was confirmed by its complete solubilization into NLC [40].

\section{FTIR Studies}

FTIR spectrum of the drug identifies its nature through clearing the functional groups that are related to the drug structure. Fig. 2(a-F) showed the IR spectra of pure caffeine, GMS, stearic acid, physical mix (1:1), blank NLC, and caffeine-loaded NLC of the optimum formula (C3).

FTIR spectra of pure caffeine showed a broad peak at $3408.42 \mathrm{~cm}^{-1}$ due to $\mathrm{N}-\mathrm{H}$ stretching vibration, aromatic $\mathrm{C}-\mathrm{H}$ stretch appeared at 3111.18 $\mathrm{cm}^{-1}$ and $2953.02 \mathrm{~cm}^{-1}$, the peak at $1661.29 \mathrm{~cm}^{-1}$ is due to $-\mathrm{C}=\mathrm{N}$ ring stretching, $1725 \mathrm{~cm}^{-1}$ ( $\mathrm{C}=0$ of $\mathrm{C} 6$-ring stretching), $1548.84 \mathrm{~cm}^{-1}(\mathrm{C}=\mathrm{C}$ stretching), and $1399 \mathrm{~cm}^{-1}$ (C-N stretching), [41], Fig. (2a).

FTIR spectrum of GMS showed a broad peak at $3315.7 \mathrm{~cm}^{-1}$ due to $(\mathrm{O}-\mathrm{H}), 2916.37 \mathrm{~cm}^{-1}$ and $2848.86 \mathrm{~cm}^{-1}$ for $(\mathrm{C}-\mathrm{H})$ stretching, $1734.8 \mathrm{~cm}^{-1}(\mathrm{C}=0)$, $1195.87 \mathrm{~cm}^{-1}$ and $1047.35 \mathrm{~cm}^{-1}$ (C-0), Fig. 2(b) [42]. FTIR spectrum of stearic acid showed the peaks at $2848.86 \mathrm{~cm}^{-1}$ and $2916.37 \mathrm{~cm}^{-1}$ which was due to the stretching vibrations of $-\mathrm{CH} 2$ groups and the peak at $1734.8 \mathrm{~cm}^{-1}$ related to a carbonyl group of stearic acid [43], Fig. 2(c).

FTIR spectrum of caffeine/physical mix at ratio (1:1), Fig. 2(d) and the optimum formulas, Fig. 2(f) showed the distinctive peaks of ingredients (GMS and stearic acid) at $2916.37 \mathrm{~cm}^{-1}$ and $2848.86 \mathrm{~cm}^{-1}$ which reveals the structural integrity of the chosen ingredients in the established formulas. IR spectrum of the optimized formulas (C3) showed peaks at $1734.8 \mathrm{~cm}^{-1}$ and no characteristic peaks related to the drug Fig. 2(f). This result confirms satisfactory solubilization and complete entrapment of drug into lipid phase that evidenced by the low intensity, slight shift, broadening, and disappearance of the drug peaks in the formula [44].

\section{$\%$ Yield, \%EE, and \%DL}

The \% yield of caffeine-loaded NLCs (C1-C8) was in the range of 90-98\%, these high yield values revealed an optimum method for NLCs preparation. The \%DL was in the range of 5.99-22.36, and the \%EE was in the range of 38.91-72.55 (Table 4). Further investigation for the effects of several factors on the \%EE of caffeine-loaded NLCs was carried out. The data was analyzed using $2^{3}$ full factorial designs at two levels and three variables strategies.

Data analysis according to the factorial design program was presented in Fig. $\mathbf{3}(\mathbf{a}, \mathbf{b}$, and $\mathbf{c})$. It was found that the lipid type, S/CoS type, and drug concentration had a significant effect on the \%EE of caffeine $(P<0.005)$.

With respect to lipid type, the results revealed that the NLCs formulas containing stearic acid showed a high entrapment efficiency (Fig. 3a). The entrapment efficiency of NLCs was improved upon increasing the fatty acid carbon chain length which led to higher hydrophobicity and thus increasing drugs residence within its core matrix [45]. 
In accordance with the effect of surfactant type (Fig. 3(b)), those formulas that were prepared with cremophore EL showed the highest capability to encapsulate the hydrophilic drugs at low drug concentration (1.5\%). The \%EE of formula C3 prepared with cremophore EL as a surfactant (72.55\% \pm 0.12) was more than \%EE of formula C1 prepared with Tween 80 (60.13\% \pm 1.34$)$. The same results were observed with C5 and C7 (Table 4$)$. Cremophore EL is identified as oxylated triglycerides of ricinoleic acid, this structure decreases the interfacial tension between the oil and aqueous phases during the emulsification, consequently, improving drug entrapment [46].

Referring to drug concentration (Fig. 3(c)), the results proved that increasing the drug concentration from 1.5 to $3 \%$ decreasing \%EE, (P<0.005), especially upon using cremophor EL/Transcutol HP as S/CoS type. The formula C3 has 22.36 and $72.55 \% \mathrm{DL}$ and \%EE, respectively, that was decreased to 7.58 and 48.96 , respectively for the formula (C4) when drug concentration increased from $1.5 \%$ to $3 \% \mathrm{w} / \mathrm{v}$. The same results were also observed upon comparing the results of $\mathrm{C} 7$ to $\mathrm{C} 8$ (Table 4). These results were contributed to the fact that increasing the amount of the drug resulted in an extra porous structure in the nanostructured lipid particles. The drug readily leaked out to the external medium through the cavities and channels filled with the drug. Moreover, upon raising drug concentration in the nanoformulations, the osmotic pressure difference between the inner and outer phases was altered, as a result of some injuries to the formed quasi-emulsion droplets, which in turn caused the drug to leak from the inner phase [47].

\section{Particle size analysis}

Table 4 presented the results of particle size and PDI of caffeine-loaded NLCs formulas (C1-C8). The particle size and PDI ranges were 240-772 nm and 0.541-0.958, respectively, revealing the existence of the drug in the nanosize range $(<1000 \mathrm{~nm})$. Figure 4 presents the data analysis according to the factorial design software. It was found that the lipid type, $\mathrm{S} / \mathrm{CoS}$ type, and drug concentration had a significant effect on particle size ( $<<0.005)$.

Concerning the lipid type, NLCs formulas prepared using GMS possessed the smaller particle size and PDI compared to those prepared using stearic acid (Fig. 4 (a) and Table 4). The addition of GMS could decrease the particle size as it has self-emulsifying property due to its structure which has saturated carbon chain length. This structure enables it to capture more drugs and have a uniform particle size in the nanosize range [48]. These findings were agreed with Gardouh, S. G. et al., [49] who found that lipid hydrophilicity and self-emulsifying properties affected by the lipid crystal's appearance (and hence the surface area) had an indirect effect on the final size of NLC dispersions.

The results presented in (Fig. 4(b) and Table 4) showed the important effect of surfactants on the NLCs particle size. The formulas, which contain Cremophore EL as surfactant exhibited particle size smaller than those prepared with Tween 80 at the two levels of drug concentrations $1.5 \%$ and $3 \% \mathrm{w} / \mathrm{v}$. Cremophore EL has more emulsification efficacy than Tween 80 that ensures particles uniformity. Comparing C1 to C5, the particle size was 585 and 400um, respectively, C2 and C6 was 772 and 696 nm, respectively), C3 and C7 was 358 and 240nm, respectively, and (C4 and C6 was 624 and 498nm, respectively. This result was attributed to molecular structure differences between both surfactants whereas; Cremophore EL had a slightly lower degree of ethoxylation and unsaturation. At the level of pharmaceutical industries, they have been dedicated much attention for the application of Cremophor EL is more than Tween 80, due to its higher emulsifying capacity and its capability to encapsulate, solubilize, and protect both lipophilic and hydrophilic compounds [50].

Concerning the drug concentration, the results showed that increasing drug concentration from $1.5 \%$ to $3 \% \mathrm{w} / \mathrm{v}$ had an obvious effect on increasing NLCs particle size (Fig. 4(c), regardless of the lipid or S/CoS types (see C1, C3, C5, and C7 in comparison to C2, C4, C6, and C8 in Table 4). These results may be due to the concept of crystallization theory which is influenced by increasing the drug concentration [51]. Higher drug concentration, higher super-saturation rate leading to higher diffusion-controlled growth and faster crystal growth as a result the agglomeration process was higher, resulting in larger particle size. These findings agreed with Dingler, A. et al., [52] who reported that the higher NLCs particle size was attributed to higher drug concentration.

From the analysis of the factorial design, it was found that only the lipid type had a significant effect on PDI (P<0.005), Fig. 5 (a). The formulas $\mathrm{C} 1$, C2, C3, and C4 prepared with stearic acid exhibited PDI of $0.839,0.829,0.912$, and 0.958 , respectively, which were higher than that exhibited by the formula prepared with GMS C5, C6, C7, and C8; $0.61,0.541,0.556$, and 0.665 , respectively. These results were attributed to the higher particle size of the formulas prepared with stearic acid more than those prepared with GMS as solid lipid. Large particles form clusters or aggregates which in turn lead to higher PDI and broad size distribution [53]. In addition, the efficacy of GMS to act as an emulsifier, provide stability to NLCs dispersions, and ensure nanoparticles homogeneity.

\section{Zeta potential measurements}

All NLCs formulas showed higher negative zeta potential (ZP) values > -19 mv (Table 4), which revealed better stability of the colloidal dispersed nanoparticles. This stability was related to electrostatic repulsion that prevents the nanoparticles from aggregation. The higher values of ZP $( \pm 30$ or more) indicate higher nanoparticle stability [54]. Table 4 and Fig. 6, formula C3 showed a slightly lower ZP of $-24.8 \pm 0.70$, than formula C4 -29.1 \pm 1.78. This may be attributed to increasing the dug concentration, decreasing the encapsulation efficiency and drug loading and at lower loading, there is a low affinity between the drug and lipid matrix, consequently, more negative charged particles (ionized drug) are released in the external medium and the drug can be retained by the electrostatic interactions [55] 
Since NLCs formulas were developed for topical application, the measurement of $\mathrm{pH}$ is an essential process to avoid skin damage or severe irritation. The $\mathrm{pH}$ of the prepared caffeine NLCs formulas was measured and was found to be in the range of (5-5.97) that mimic the $\mathrm{pH}$ of the cuticle as shown in Table 4. Electrical conductivity is utilized for the evaluation of the electro-conductive behavior of the compounds. The conductivity values of the NLCs formulas were high and ranged from 105.36 to $197.33 \mu \mathrm{S} / \mathrm{cm}$, Table 4. These elevated values are due to high water content which enables ions to move more freely. It was found that conductivity raised with increasing the drug concentration and diminished with increase \% encapsulation efficiency. The formula C2 $(197.33 \pm 9.29 \mu \mathrm{S} / \mathrm{cm})$ increased by 0.8 fold than the formula $\mathrm{C} 1(158.13 \pm 7.88 \mu \mathrm{S} / \mathrm{cm})$. These findings were attributed to the dependence of conductivity on the concentration, mobility, and valence states of the ionized species in a solution. Increasing the amount of the drug led to a higher concentration of free and unbounded drug ions in water, which finally resulted in higher conductivity [56].

\section{In-vitro drug release studies}

The release pattern of caffeine-loaded NLCs formulas compared to the market formula was investigated over $2 \mathrm{hr}$ and presented in Fig. 7. The results revealed that all tested formulas allowed for high \% drug release during the first $0.25 \mathrm{~min}$. The market formula released about $47.8 \%$, whereas, NLCs exhibited \% drug release in the range of 35.09-55.88. At that time, the drug release was expressed as rapid release in which the drug was released from the exterior shell of NLCs, then release occurred from the inner core. This fast release could be due to the increase in the chemical potential gradient, which resulted in escaping of the encapsulated active ingredients gradually from NLCs into the external phase. At this stage, the release rate would be much higher as less energy was required to overcome the phase barrier for it to be released to the continuous phase [57]. From the analysis of the factorial design (Fig. 8 a, b, and c) it was found that the lipid type, surfactant type, and drug concentration had a significant effect on the \% release $(\mathrm{P}<0.005)$. Regarding the lipid type, the formulas C7 and C8 prepared by using GMS exhibited a \% release of $97.34 \pm 1.24$ and $99.65 \pm 9.99$, respectively after the first hour. This percentage presents 1.3 and 1.1 fold than that released by the formulas $\mathrm{C} 3$ and $\mathrm{C} 4$ (stearic acid); $72.8 \pm 3.18$ and $89.24 \pm 3.04$, respectively $\left(P^{\star \star \star}<0.001\right)$. All the formulas prepared with stearic acid delay the $\%$ drug release than those prepared with GMS.

The effect of surfactant type on the \% of drug release appeared clearly with the NLCs formulas containing stearic acid. The result clearly revealed that the formulas prepared with Cremophore EL allowed more rapid drug release. Upon comparing the percentage of drug release after $1 \mathrm{hr}$, the formula (C3) showed \% release $(72.8 \pm 3.18)$ that presents 1.08 fold of the formula C1 $(67.4 \pm 2.20)$. The formula C4 (89.24 \pm 3.04$)$ was 1.05 fold of the formula C2 (85.2 \pm 1.72$),\left(P^{* \star *}<0.001\right)$. These results were related to the higher emulsifying properties of cremophore EL. The penetration activity of Cremophor EL has a potential role in increasing the fluidity of the lipid bilayer, hence increasing the drug release [58]. All the formulas prepared with GMS as solid lipid showed nearly $100 \%$ release after $1 \mathrm{hr}$.

Regarding the drug concentration, upon increasing the drug concentration from 1.5 to $3 \%$, the \% drug release slightly increased. After $1 \mathrm{~h}$, the \% of drug release from formula $\mathrm{C} 2$ was greater than $\mathrm{C} 1(85.2 \pm 1.72>67.4 \pm 2.20)$ and $\mathrm{C} 4$ than $\mathrm{C} 3(89.24 \pm 3.04>72.8 \pm 3.18)$, respectively $(\mathrm{P} \star \star \star<<0.001)$. The faster release is achieved by higher drug concentration when the adsorption of the drug particles which are weakly bound to the nanocarriers rather than to the drug incorporated in polymer nanoparticles [59].

\section{Ex-vivo skin permeation studies}

Permeation studies were done on the optimized formula, which had the smallest particle size and reasonable \% EE. The formulas $\mathrm{C} 3$ and $\mathrm{C7}$ showed particle size $358.6 \pm 1.45,240.4 \pm 22.87 \mathrm{~nm}$, respectively, and \% EE $72.55 \% \pm 0.12,67.20 \% \pm 5.98$. The \% of drug release for C3 and C7 was $84.28 \pm 3.18$ and $100.75 \pm 0.77$ after $2 \mathrm{hr}$, respectively. Consequently, a permeation study was performed on these optimized formulas in comparison to their market formulas. Permeation profiles present the cumulative amounts of caffeine permeated from NLCs formulas and market per unit time for $24 \mathrm{hr}$ are presented in Fig. 9, Table 5.

The formula C3 showed the highest amount permeated drug through 24hr. The tested formula could be arranged discerningly as follows: C3 > C7 > market; the cumulative amount permeated $\left(\mu \mathrm{g} / \mathrm{cm}^{2}\right)$ was as follows: $150.832>87.2804>55.514$, respectively, Table 5 . The amount of drug permeated from formulas $\mathrm{C} 3$ and $\mathrm{C} 7$ present 2.7 and 1.6 fold of market, respectively. These results were due to the mechanism of oleic acid as a chemical permeation enhancer in the NLCs formulas, Its absorption by stratum corneum reduces lipid temperature changes and so, improves the permeation of the drug. Additionally, it decreases the viscosity of lipids of the superficial layer [60]. Cremophor EL and Transcutol HP as S/CoS mixture in NLCs formulation had an efficient effect on drug permeation, which in turn allow better permeation profile [9]. Cremophor EL increases the epithelial permeation through disturbing connections in the epithelial wall, enabling drug transportation via the membrane. So it efficaciously improved topical permeation of caffeine compared to market missing Cremophor EL [61].

Permeability parameters for caffeine, including; drug flux $\left(\mathrm{J}_{\mathrm{ss}}\right)$, permeation coefficient $(\mathrm{Kp})$, and enhancement ratio (Er) are presented in Table 5. All parameters significantly increased with NLCs formulas in comparison to the market formula $(P<0.001)$. The values $6.1375\left(\mu \mathrm{g} / \mathrm{cm}{ }^{2} / \mathrm{h}\right), 2.713$, and $165 \times 10^{-2}\left(\mathrm{~cm}^{2} / \mathrm{h}\right)$ were recorded for formula C3 as the highest flux $\left(\mathrm{J}_{\mathrm{ss}}\right)$, enhancement ratio (Er), and permeation coefficient (Kp), respectively.

At the end of the permeation experiment, the efficacy of caffeine NLCs formulas to be accumulated in skin layers was estimated. The amount of accumulated caffeine in rat skin after subjecting to NLCs formulas (C3 and C7) and the market formula for 24hr was determined, Table 5. The amount of caffeine accumulated in the skin following topical delivery of NLCs formulas was clearly high compared to the market formula. The amounts of accumulated caffeine from C3 and C7 were; $4830.4716 \pm 41.461$ and $4398.359 \pm 298.8837 \mu \mathrm{g} / \mathrm{cm}^{2}$ after $24 \mathrm{hr}$, respectively, These amount

Page $10 / 27$ 
presents about 3.1 and 2.8 times enhancement over the market formula (1547.670 $\left.\pm 125.3430 \mu \mathrm{g} / \mathrm{cm}^{2}\right)$. According to Fei, H. et al. [62], NLCs enhance the occlusive effect, film formation, and close contact with SC of skin and thus increase the amount of entrapped drug into the skin, improving its penetration.

\section{Transmission electron microscopy studies}

Morphology of caffeine NLCs optimized formula (C3) scanned by TEM revealed that it was successfully formulated with a smooth surface, distinct integrity, and spherical shape particles, (Fig. 10). It also showed the sizes ranges (300-500 nm), without obvious aggregation [63].

\section{Stability studies of the optimized formula (C3) as per ICH guidelines}

Table 6, presents the results of stability studies of the NLCs optimized formula (C3). There was no remarkable alteration in color, pH, particle size, PDI, zeta potential, and \% EE. Additionally, it kept its homogeneity without the appearance of any phase separation or clog formation, which proved the good physical stability of the NLCs optimized formula.

\section{Confocal Laser Scanning Microscopy (CLSM)}

To evaluate the drug distribution performance when loaded on NLCs within the skin layers (epidermis, dermis, and hypodermis), CLSM was employed The CLSM images of perpendicular slices of rat skin gotten after 48hr application of caffeine RB-NLCs (C3) are shown in Fig. 11(a). The NLC formula (C3) loaded with RB showed higher fluorescence intensity of RB in the hypodermal layer, whereas the drug was distributed through all layers of the skin, indicating high skin targeting efficiency and highly permeation. These results are consistent with previously reported findings of Pople and Singh [64]. Control formula loaded with RB in which drug was applied as a suspension in aqueous media showed drug distribution in the epidermal layer only with low permeation efficiency, Fig. 11(b). Accordingly, this experimental part clearly proved the potential efficacy of NLCs nanoformulation as a skin targeting drug delivery system with a small mean particle size of $419 \mathrm{~nm}$. Conjugation of drug loaded-NLCs with RB has no effect on the particle size of the NLCs.

\section{In-vivo study}

\section{Morphological examination of rat's dorsal skin in different groups}

This experimental part has crucial importance for evaluating the efficacy of different tested formulas on rat hair growth. The effect of caffeine NLCs optimum formula (C3), blank, and market formulas on the hair growth were compared to control (un-treated rats) Fig. 12 (a-d). The photographs (a-d) showed the thick hair of dorsal rats' skin at zero-day before chemotherapeutic induction in different rat groups treated with; (a) the optimum formula C3, (b) blank formula, (c) market formula, and (d) control. Fig.12(e-h) the rat's bald skin without hairs after chemotherapeutic induction with etoposide $(1.5 \mathrm{mg} / \mathrm{kg}$ ), once daily for three consecutive days. Fig. 12(i-I), presents hair growth for rats after 30 days of treatment. Control group (Fig. 12(i) presents minimum hair growth. The rat group treated with the formula C3 exhibited complete and heavy hair growth (Fig. 12(j)) in comparison to the market formula (Fig. 12(k) and the blank formula (Fig. 12(l) that showed incomplete hair growth. Hair regrowth was noticed during the whole treatment period. The effective NLCs permeation and fast drug release confirm well therapeutic efficiency. The improvement of drug activity of NLCs formula was attributed to the presence of oleic acid, that acts as a permeation enhancer due to its good wetting and moisturizing properties [65]. Oleic acid permits drug permeation through skin layers and in addition, it moistens the dry hair. The lower efficacy of the market formula was related to solvent evaporation that not only decreases drug permeation but also yields dry skin. The blank formula that was presented in aqueous media lacks to permeation enhancer.

\section{Histopathological evaluation of the skin specimens}

The effect of topical application of caffeine-loaded NLCs formulas on hair growth was studied through the histopathological examination of the skin layers, Fig. 13 (a-d). Fig. 13 (a, b) showed the histopathological examination of the normal skin specimens with a normal histopathological structure of the epidermal layer, underlying dermis, sebaceous gland, and subcutaneous tissue. Also, it showed multiple mature hair follicles with hair shaft and bulb that are characterized by spindle-like dermal papilla (DP) and Y-shaped melanin granules around the DP without ectopic melanin in the bulb. While Fig. 13 (c, d) showed the histological examination of skin specimens after 3 days of chemotherapeutic induction, a dystrophic change of hair follicles was observed which is characterized by the presence of ectopic melanin granules and swollen DP. These melanin granules are smaller than keratinocyte nuclei and present as clumps in the bulb and hair shaft. The hair follicles showed a catagen-like structure with a ball-like small DP [66]

Fig. 14 (a,d,g, and i) presents biopsy specimens of rat skin after 10 days of treatment; (a) the optimum formula C3, (d) blank formula, (g) market formula, and (i) control. The skin of rats in the control group showed reduction and atrophy in the hair follicles (decrease in size and number). The animal group treated with optimum NLCs formula (C3) showed multiple hair follicles of the dermis. The group treated with blank formula showed acanthosis in the epidermis with the appearance of mature hair follicles. The animals treated with market caffeine showed atrophy in most hair follicles. Fig. 14 (b,e,h, and k) presents biopsy specimens of rats' skin after 20 days of topical treatment. The control group (Fig. 14 (k) showed few immature hair follicles of the dermis, and the group treated with optimum NLCs formula (C3) showed multiple numbers of mature and immature hair follicles of the dermis (Fig.14 (b). Skin rats of the group treated with blank formula showed few appearances of immature hair follicles and less 
mature ones (Fig. 14 (e). The rat group treated with market caffeine showed the appearance of multiple mature hair follicles but less than the group treated with the NLCs optimum formula C3 (Fig. 14 (h).

After 30 days of topical treatment, the animals were sacrificed and the histopathological examination of rats' skin specimens was presented in Fig. 14 (c,f,i, and I). The skin of rats in the control group (Fig. 14 (I) showed focal necrosis and ulceration in the epidermis, acanthosis, and invagination of the epidermis and dermis. The subcutaneous tissue showed the excessive formation of tissue granulation with inflammatory cells infiltration. Fig. 14 (c) is for skin rats of the group treated with NLC formula C3. It showed multiple numbers of mature and immature hair follicles of the dermis. Skin rats of the group treated with the blank of formula C3 showed less appearance of mature hair follicles and less immature ones (Fig. 14 ( $f$ ). Skin rats of the group treated with market caffeine showed the appearance of multiple mature hair follicles but less than that recognized in the group treated with optimum NLCs formula of caffeine (C3), Fig. 14 (i). The appearance of mature and immature hair follicles for skin rats in different groups can be arranged descendingly as follows; group treated with NLCs optimum formula (C3) > group treated with market formula > group treated with blank formula> group treated with control. The appearance of acanthosis, necrosis and granulation tissue formation with inflammatory cells infiltration for skin rats in different groups can be arranged descendingly as follows; group treated with control > treated with blank formula> treated with market formula $>$ treated with optimum formula (C3).

\section{Conclusion}

In the present study, caffeine-loaded NLCs were formulated using a combination of stearic acid or GMS and oleic acid: garlic oil (1:1) as lipid phase. The pre-emulsion ultrasonication technique was employed. Tween 80 and cremophore EL and Transcutol HP were used as surfactants and cosurfactant, respectively. The factors affecting the NLCs formulation were optimized using a factorial design program. The FTIR study of pure caffeine and excipients confirmed that there was no remarkable chemical interaction between them. DSC studies confirm the transformation of the crystalline nature of the drug into amorphous nature. The TEM analysis showed the NLCs were formulated and having a spherical shape. The results of zeta potential predicted good particle stability because the repulsive forces prevent aggregation over time. The results of the present study suggest caffeine NLCs as promising carriers for topical delivery of drugs applied for alopecia treatment. The NLCs carriers promote a higher growth rate of hair over the currently marketed formula of caffeine.

\section{Declarations}

\section{Ethics approval and consent to participate}

The animal protocol was carried out according to the experimental protocol was approved by the Animal Care Ethics Committee, Faculty of Pharmacy, Cairo University No (88) for 31/12/2018.

\section{Consent for publication}

All authors consent for publishing this work.

\section{Availability of data and material}

The data sets generated during this work can be available upon request.

\section{Competing interests:}

The authors declare no competing interests.

\section{Funding}

No funding.

\section{Author contribution}

Prof. Dr. Amna Makky: conceptualization, investigation, visualization, supervision, review and editing original draft. Prof. Dr. Eman Saddar el-leithy: investigation, supervision, visualization and writing original draft. Dr. Abeer Khattab: investigation, conceptualization and writing original draft. Dr. Doaa Galaa: investigation and writing original draft.

\section{Acknowledgements}

We would like to acknowledge Egyptian drug authority for support.

\section{References}


1. Ruela ALM, Perissinato AG, Lino MES, et al. Evaluation of skin absorption of drugs from topical and transdermal formulations. Braz. J. Pharm. Sci. 2016;52(3): 527-44.

2. Sreeraj SR, Bharati B, Ipseeta R. A review on ultrasound parameters and methods of application in transdermal drug delivery. Int J Health Sci \& Res. 2015;5: 476-85.

3. Escobar-Chavez J, Díaz R, Rodriguez-Cruz IM, et al. Nanocarriers for transdermal drug delivery. Research and Reports in Transdermal Drug Deliv. 2012; 2012 (1): 3-17.

4. Contri RV, Fiel LA, Pohlmann AR, et al. Transport of substances and nanoparticles across the skin and in vitro models to evaluate skin permeation and/or penetration. In: Beck R, Guterres S, Pohlmann A, editors. Nanocosmetics and nanomedicines. Berlin: Springer; 2011. pp. 3-35.

5. Alam Z, Sadia TA, Maimoona M, et al. Potential of nanoparticulate carriers for improved drug delivery via skin, J. Pharm. Invest. 2019; 49: 485517.

6. McElwee KJ, Gilhar A, Tobin DJ. What causes alopecia areata? Exp Dermatol. 2013; 22:609-26.

7. Mahmoud HT, Sally AA, Mohamed AE, et al. Non-ionic surfactant based vesicular drug delivery system for topical delivery of caffeine for treatment of cellulite: design, formulation, characterization, histological anti-cellulite activity and pharmacokinetic evaluation. Drug Dev \& Ind Pharm. 2018; 44: 158-71.

8. Bansal M, Pandey S, Manchanda K. Role of caffeine in the management of androgenetic alopecia. Int J Trichol. 2012; 4(3): 185-7.

9. Eman SE, Amna MM, Abeer MK, et al. Optimization of nutraceutical coenzyme Q10 nanoemulsion with improved skin permeability and antiwrinkle efficiency. Drug Dev \& Ind Pharm. 2018; 44: 316-28.

10. Suraj S, Som KR, Prashanta P, et al. A simple HPLC method for determination of caffeine content in tea and coffee. J Food Sci Techol Nepal. 2016; 9: 74-8.

11. Shete H, Patravale VS. Long chain lipid based tamoxifen NLC. Part I: Preformulation, formulation development and physicochemical characterization. Int J Pharm. 2013; 454: 573-8.

12. Prakash CG, Anupriya K, Prashant P. Designing and characterization of econazole nitrate nanostructured lipid carriers gel for topical delivery. Eur J Pharm \& Medical Res. 2018;5: 559-67.

13. Edit B, John EAC, Krisztina TN. Study of equilibrium solubility measurement by saturation shake-flask method using hydrochlorothiazide as model compound. J Pharm and Biomed Ana. 2008; 46: 335-41.

14. Eman SE, Rania SA. Lipid nanocarriers for tamoxifen citrate/coenzyme Q10 dual delivery. J Drug Deliv Sci Tech. 2017; 41: 239-50.

15. Neha M, Manju M, Harish P. Formulation Development and optimization of efavirenz loaded SLNs and NLCs using plackett-burman design and its statistical elucidation. Int J Pharma Res Health Sci. 2018; 6 (2): 2379-88.

16. Shailesh LP, Snehal RP, Surendra G. Development and evaluation of nanostructured lipid carriers-based gel of isotretinoin. Particulate science and technol. 2018; 36(7): 832-43.

17. Sare A, Jaleh V, Farshid H, et al. Optimization of LDL targeted nanostructured lipid carriers of 5-FU by a full factorial design. Advanced Biomedical Res. 2012;1(3): 1-11.

18. Harshita M, Abul B, Rizwanullah M, et al. Paclitaxel-loaded nanolipidic carriers with improved oral bioavailability and anticancer activity against human liver carcinoma. AAPS PharmSciTech. 2019; 20 (87):1-14.

19. Amr EK, Maha F, Dina L. Curcumin-loaded nanostructured lipid carriers prepared using Peceol ${ }^{\mathrm{TM}}$ and olive oil in photodynamic therapy: development and application in breast cancer cell line. Int. J. Nanomedicine. 2019; 14: 5073-85.

20. Mohammed E, Hany MI, Mohammed AA, et al. Atorvastatin-loaded nanostructured lipid carriers (NLCs): strategy to overcome oral delivery drawbacks. Drug delivery. 2017;24(1): 932-41.

21. Soni K, Mujtaba A, Kohli K. Lipid drug conjugate nanoparticle as a potential nanocarrier for the oral delivery of pemetrexed diacid: formulation design, characterization, ex vivo, and in vivo assessment. Int J Biol Macromol. 2017;103: 139-51.

22. Jihui Z, Xianghua P, Xiaoqin S, et al. Podophyllotoxin-loaded nanostructured lipid carriers for skin targeting: in vitro and in vivo studies. Molecules. 2016;21: 1-11.

23. Wikramanayake TC, Amini S, Simon J, et al. A novel rat model for chemotherapy-induced alopecia. Clin Exp Dermatol. 2012; 37(3): 284-9.

24. Jae CY, Bo AK. In vivo and In vitro hair growth promotion effects of extract from Glycine soja Siebold et Zucc. J Appl Biol Chem. 2016 ; 59 (2): 137 $-43$.

25. Ghada K, Hesham E, Shawky MS. Chitosan-stabilized selenium nanoparticles attenuate acrylamide-induced brain injury in rats. J. Food Biochem. 2020; 44: 1-10.

26. Shang V, Cao S, Xu X, et al. Bioactive compounds and biological functions of Garlic (Allium sativum L.). Foods. 2019 ; 8 (7): 1-31.

27. Zhao X, Liu JP, Zhang X, Li Y, Enhancement of transdermal delivery of theophylline using microemulsion vehicle. Int J Pharm. 2006; 327 : 58-64.

28. Ashu M, Sara UVS, Asgar A, et al. Status of fatty acids as skin penetration enhancers; A review. Curr Drug Deliv. 2009; 6: 274-9.

29. Seo YG, Kim DH, Ramasamy T, et al. Development of docetaxel-loaded solid self-nanoemulsifying drug delivery system (SNEDDS) for enhanced chemotherapeutic effect. Int J Pharm. 2013; 452(1-2): 412-20.

Page 13/27 
30. Amanda VF, Chinna RP, Ruchi V, et al. Design, preparation and in vitro characterizations of fluconazole loaded nanostructured lipid carriers. Braz. J. Pharm. Sci. 2020;56: 1-14.

31. Fathi HA, Allam A, Elsabahy M, et al. Nanostructured lipid carriers for improved oral delivery and prolonged antihyperlipidemic effect of simvastatin. Colloids Surf. B Biointerfaces. 2018;162: 236-45.

32. Aindrilla SD, Kisan RJ, Vilasrao JK. Development and in vitro evaluation of nanostructured lipid carriers (NLCs) of gliclazide. World J. Pharm Pharm Sci. 2016;5: 1725-39.

33. Ketan TS, Anuradha KG, Jignasa KS. Drug Solubility: Importance and enhancement techniques. ISRN Pharmaceutics. 2012 ; 2012 : 1-10.

34. Rania H, Areeg A, Suhair S, et al. PH-dependent solubility and dissolution behavior of Carvedilol, case example of a weakly basic BCS Class II Drug. AAPS Pharm Sci Tech. 2015;17: 418-26.

35. Mayer LD, Tai LC, Bally MB, et al. Characterization of liposomal systems containing doxorubicin entrapped in response to $\mathrm{pH}$ gradients. Biochimica et Biophysica Acta. 1990;1025: 143-51.

36. Mahboobeh N, Shiva G, Hossein A, et al. Antifungal activity of Zataria multiflora essential oil-loaded solid lipid nanoparticles in-vitro condition. Iran J Basic Med Sci. 2016; 19 (11): 1231-7.

37. Carmelo P, Alessia O, Giorgia GT, et al. Design of solid lipid nanoparticles for caffeine topical administration. Drug Deliv. 2016 ; 23 (1): $36-40$.

38. Freitas C, Müller RH. Correlation between long-term stability of solid lipid nanoparticles (SLN(TM)) and crystallinity of the lipid phase. Eur. J. Pharm. Biopharm. 1999;47: 125-32.

39. Shamsunder SD, Sandip SC, Krutika KS, et al. Solid lipid nanoparticles and nanosuspension formulation of Saquinavir: preparation, characterization, pharmacokinetics and biodistribution studies. J. Microencapsulation. 2011; 28(6): 515-27.

40. Shubham U, Ram KS, Amit R, et al. Preparation and characterization of minoxidil loaded nanostructured lipid carrier gel for effective treatment of alopecia. Saudi Pharm J. 2013; 21: 379-85.

41. Rajam K, Rajendran S, Nazeera BN. Effect of Caffeine-Zn ${ }^{2+}$ system in preventing corrosion of Carbon Steel in well water. Hindawi Publishing Corporation. J. Chem. 2013; 2013: 1-11.

42. Li H, Tao W. Preparation of glycerol monostearate from glycerol carbonate and stearic acid. RSC Adv. 2016; 6: 34137-45.

43. Yuan-Xian Z, Xiu-Wen Z, Zhao-Qing L, et al. Preparation and enhancement of thermal conductivity of heat transfer oil-based mos2 nanofluids. Hindawi Publishing Corporation, J. Nanomaterials. 2013; 2013: 1-6.

44. Saba-Khan MS, Mohammad F, Sanjula B, et al. Tacrolimus-loaded nanostructured lipid carriers for oral delivery-optimization of production \& characterization. Eur. J. Pharm. Biopharm. 2016;108: 277-88.

45. Xie S, Zhu L, Dong Z, et al. Preparation, characterization and pharmacokinetics of enrofloxacin-loaded solid lipid nanoparticles: Influences of fatty acids. Colloids Surf. B Biointerfaces. 2011; 83: 382-7.

46. Gelderblom H, Verweij J, Nooter K, et al. Cremophor EL: the drawbacks and advantages of vehicle selection for drug formulation. Eur. J. Cancer. 2001; 37: 1590-8.

47. Leena P, Johanna A, Samuli $H$, et al. Improved entrapment efficiency of hydrophilic drug substance during nanoprecipitation of poly(I)Iactide nanoparticles. AAPS PharmSciTech. 2004; 5 (1): 115-20.

48. Anagha B, Shivanand H, Devanna N, et al. Influence of various process variables and formulation excipients on the engineering of sertaconazole solid lipid nanoparticles. IOSR Journal of Pharmacy. 2016;6 (7): 51-63.

49. Gardouh A, Gad S, Ghonaim H, et al. Design and characterization of glyceryl monostearate solid lipid nanoparticles prepared by high shear homogenization. Br. J Pharm Res. 2013; 3 (3): 326-4.

50. Abo Enin HA. Self-nanoemulsifying drug-delivery system for improved oral bioavailability of rosuvastatin using natural oil anti-hyperlipdemic. Drug Dev. Ind. Pharm.2015; 41: 1047-56.

51. Vijay A, Meenakshi B. Preparation and optimization of esomeprazole nanosuspension using evaporative precipitation-ultrasonication. Tropical J. Pharm. Res. 2014; 13 (4): 497-503.

52. Dingler A, Blum RP, Niehus H, et al. Solid lipid nanoparticles (SLNTM/LipopearlsTM); a pharmaceutical and cosmetic carrier for the application of vitamin $\mathrm{E}$ in dermal products. J. Microencapsul. 1999; 16:751-67.

53. Carine S, Alia J, Hatem F, et al. Preparation and characterization of clove essential oil-loaded liposomes. Food Chemist. 2015;178: 52-6.

54. Shady AS, Zeinab NM, Zeinab AM, et al. DOE, formulation, and optimization of Repaglinide nanostructured lipid carriers. J. Appl. Pharm. Sci. 2018; 8 (10): 8-16.

55. Hirsjärvi S, Peltonen L, Hirvonen J. Layer-by-layer polyelectrolyte coating of low molecular weight poly (lactic acid) nanoparticles. Colloid. Surface. B. 2006; 49: 93-9.

56. Abeer K, Soha I. Formulation and evaluation of oxiconazole nitrate mucoadhesive nanoemulsion based gel for treatment of fungal vaginal infection. Int. J. Pharm. Pharm. Sci. 2016; 8: 33-40.

57. Yew HC, Misran M. Characterization of fatty acid based nanostructured lipid carrier (NLC) and their sustained release properties. Prog Drug Discov Biomed Sci. 2019; 2 (1): 1-7.

Page 14/27 
58. Sara MS, Nermin MS, Bassant MMI, et al. Novel intranasal drug delivery: geraniol charged polymeric mixed micelles for targeting cerebral insult as a result of ischaemia/reperfusion, Pharmaceutics. 2020;12 (1): 76-98.

59. Xiao-Yun L, Dao-Cheng W, Zheng-Jun L, Guo-Qiang C. Polymer Nanoparticles. Progress in Molecular Biology and Translational Science. 2011; Ch. 7, 104: 299-323.

60. Zoraida PA. Targeted drug delivery. Nanomaterials for Medical Applications. 2013; ch.5: 181-234.

61. Wessam HA, Sally AE, Abdulaziz MA. Formulation and in vivo assessment of terconazole-loaded polymeric mixed micelles enriched with Cremophor EL as dual functioning mediator for augmenting physical stability and skin delivery. Drug deliv. 2018; 25(1): 484-92.

62. Fei H, Ran Y, Xin C, et al. Sanming, Nanostructured lipid carriers (NLC) based topical gel of flurbiprofen: Design, characterization and in vivo evaluation. Int. J. Pharm. 2012; 439: 349-57.

63. Rendra PT, Yeyet CS, Sasanti TD. Formulation, characterization, and in vitro skin diffusion of nanostructured lipid carriers for deoxyarbutin compared to a nanoemulsion and conventional cream. Scientia Pharmaceutica. 2016; 84: 634-45.

64. Pople PV, Singh KK. Development and evaluation of colloidal modified nanolipid carrier: Application to topical delivery of tacrolimus, Part II-In vivo assessment, drug targeting, efficacy, and safety in treatment for atopic dermatitis. Eur. J. Pharm. Biopharm. 2013; 84: 72-83.

65. Zdziennicka A, Szymczyk K, 'nczuk BJ, et al. Surface, volumetric, and wetting properties of oleic, linoleic, and linolenic acids with regards to application of canola oil in diesel engines. Appl. Sci. 2019; 9: 1-11.

66. Ji-Seon Y, Mira C, Chang YS, et al. Development of a model for chemotherapy-induced alopecia: profiling of histological changes in human hair follicles after chemotherapy. J Investigative Dermatol. 2016; 136: 584-92.

\section{Tables}

Table 1 Variables and their constraints in $2^{3}$ factorial design

\begin{tabular}{|lll|}
\hline Independent variables & Lower level & Upper level \\
\hline Type of lipid & Stearic acid & GMS \\
\hline Type of Surfactant & Tween 80/Transcutol HP & Cremophore EL/Transcutol HP \\
\hline Drug concentration & $1.5 \%$ & $3 \%$ \\
\hline Dependent variables & Goals & \\
\hline Entrapment efficiency $(\%)$ & Maximize & \\
\hline Particle size $(\mathrm{nm})$ and PDI & Minimize & \\
\hline Drug release $\%$ & Optimum & \\
\hline
\end{tabular}


Table 2

Solubility of caffeine in the different excipients at $25^{\circ} \mathrm{C}$

\begin{tabular}{|c|c|c|}
\hline Vehicle type & Vehicle & Solubility $(\mathrm{mg} / \mathrm{g}) \pm$ S.D \\
\hline \multirow[t]{12}{*}{ Oils } & Oleic acid & $17.04 \pm 0.715$ \\
\hline & Caproyl 90 & $12.99 \pm 0.359$ \\
\hline & $\mathrm{O}: \mathrm{G}(2: 1)$ & $6.370 \pm 1.150$ \\
\hline & Labrafil M1944 & $5.113 \pm 0.490$ \\
\hline & Jojoba oil & $4.620 \pm 0.440$ \\
\hline & $\mathrm{O}: \mathrm{G}(1: 1)$ & $4.070 \pm 0.540$ \\
\hline & Amla oil & $1.680 \pm 0.119$ \\
\hline & Rosemary oil & $1.635 \pm 0.156$ \\
\hline & CCTG & $1.243 \pm 0.238$ \\
\hline & $\mathrm{O}: \mathrm{G}(1: 2)$ & $0.890 \pm 0.093$ \\
\hline & IPM & $0.253 \pm 0.029$ \\
\hline & Garlic oil & $0.150 \pm 0.022$ \\
\hline \multirow[t]{2}{*}{ Surfactants } & Tween 80 & $8.870 \pm 0.490$ \\
\hline & Cremophor EL & $8.660 \pm 0.756$ \\
\hline \multirow[t]{3}{*}{ Co-surfactants } & Transcutol HP & $25.82 \pm 0.0832$ \\
\hline & Span 20 & $14.20 \pm 0.448$ \\
\hline & Span 80 & $6.250 \pm 0.680$ \\
\hline \multirow[t]{2}{*}{ Solid lipids } & Stearic acid & $47.11 \pm 3.048$ \\
\hline & GMS & $32.67 \pm 2.955$ \\
\hline \multicolumn{3}{|c|}{ * O: Oleic acid, G: Garlic oil, CCTG: Caprylic/capric triglyceride. } \\
\hline \multicolumn{3}{|c|}{$\star$ Each value presents the mean of triplicate $(n=3) \pm$ S.D. } \\
\hline
\end{tabular}

Table 3 Solubility of caffeine in different buffer systems at certain pHs and different ionic strengths

\begin{tabular}{|c|c|c|c|c|}
\hline \multirow[t]{2}{*}{ Buffer } & \multicolumn{4}{|c|}{ Solubility $(\mathrm{mg} / \mathrm{g})$ in buffers with different ionic strengths } \\
\hline & $50 \mathrm{mM}$ & $100 \mathrm{mM}$ & $150 \mathrm{mM}$ & $200 \mathrm{mM}$ \\
\hline Phosphate buffer at $\mathrm{pH} 7.4$ & $4.565 \pm 0.178$ & $2.743 \pm 0.11$ & $2.891 \pm 2.80$ & $2.146 \pm 0.177$ \\
\hline Phosphate buffer at pH 7.8 & $4.541 \pm 0.206$ & $3.611 \pm 0.31$ & $1.978 \pm 0.09$ & $1.413 \pm 0.073$ \\
\hline Carbonate buffer at $\mathrm{pH} 10.8$ & $3.320 \pm 0.170$ & $2.721 \pm 2.60$ & $1.614 \pm 0.87$ & $0.801 \pm 0.059$ \\
\hline
\end{tabular}

*Each value presents the mean of triplicate $(n=3) \pm$ S.D 
Table 4

Composition of caffeine loaded NLCs formulas and characterization parameters.

\begin{tabular}{|c|c|c|c|c|c|c|c|c|c|c|c|}
\hline $\begin{array}{l}\text { Formula } \\
\text { code }\end{array}$ & $\begin{array}{l}\text { Lipid } \\
\text { type }\end{array}$ & S/CoS type & $\begin{array}{l}\text { Drug } \\
\text { conc. } \\
(\% w / v)\end{array}$ & $\begin{array}{l}\text { \%Yield } \\
\pm \text { S.D }\end{array}$ & $\begin{array}{l}\text { \%DL } \pm \\
\text { S.D }\end{array}$ & $\begin{array}{l}\% \mathrm{EE} \\
\pm \mathrm{S} . \mathrm{D}\end{array}$ & $\begin{array}{l}\text { Particle } \\
\text { size } \\
(\mathrm{nm}) \pm \\
\text { S.D }\end{array}$ & $\begin{array}{l}\text { PDI } \\
\pm \text { S.D }\end{array}$ & 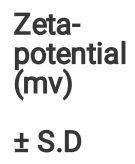 & $\begin{array}{l}\text { pH } \\
\pm \\
\text { S.D }\end{array}$ & $\begin{array}{l}\text { Electroconductivity } \\
(\mu \mathrm{S} / \mathrm{cm}) \\
\pm \text { S.D }\end{array}$ \\
\hline C1 & $\begin{array}{l}\text { SA:O: G } \\
\text { 70:15:15 }\end{array}$ & $\begin{array}{l}\text { Tween } \\
\text { 80/Transcutol } \\
\text { HP }\end{array}$ & 1.5 & $\begin{array}{l}99.3 \pm \\
1.66\end{array}$ & $\begin{array}{l}19.42 \pm \\
0.43\end{array}$ & $\begin{array}{l}60.13 \\
\pm 1.34\end{array}$ & $\begin{array}{l}585.4 \pm \\
45.9\end{array}$ & $\begin{array}{l}0.83 \\
\pm \\
0.093\end{array}$ & $\begin{array}{l}-33.0 \pm \\
0.99\end{array}$ & $\begin{array}{l}5.64 \\
\pm \\
0.56\end{array}$ & $158.13 \pm 7.88$ \\
\hline $\mathrm{C} 2$ & $\begin{array}{l}\text { SA:O: G } \\
70: 15: 15\end{array}$ & $\begin{array}{l}\text { Tween } \\
\text { 80/Transcutol } \\
\text { HP }\end{array}$ & 3 & $\begin{array}{l}95.51 \pm \\
8.55\end{array}$ & $\begin{array}{l}8.88 \pm \\
0.19\end{array}$ & $\begin{array}{l}58.09 \\
\pm 1.16\end{array}$ & $\begin{array}{l}696.6 \\
\pm 20.80\end{array}$ & $\begin{array}{l}0.82 \\
\pm \\
0.068\end{array}$ & $\begin{array}{l}-32.3 \pm \\
1.09\end{array}$ & $\begin{array}{l}5.53 \\
\pm \\
0.46\end{array}$ & $197.33 \pm 9.29$ \\
\hline C3 & $\begin{array}{l}\text { SA:O: G } \\
70: 15: 15\end{array}$ & $\begin{array}{l}\text { Cremophor } \\
\text { EL/Transcutol } \\
\text { HP }\end{array}$ & 1.5 & $\begin{array}{l}98.9 \pm \\
2.90\end{array}$ & $\begin{array}{l}22.36 \\
\pm \\
0.021\end{array}$ & $\begin{array}{l}72.55 \\
\pm 0.12\end{array}$ & $\begin{array}{l}358.6 \pm \\
1.45\end{array}$ & $\begin{array}{l}0.91 \\
\pm \\
0.030\end{array}$ & $\begin{array}{l}-24.8 \pm \\
0.70\end{array}$ & $\begin{array}{l}5.97 \\
\pm \\
0.39\end{array}$ & $105.36 \pm 7.07$ \\
\hline C4 & $\begin{array}{l}\text { SA:O: G } \\
70: 15: 15\end{array}$ & $\begin{array}{l}\text { Cremophor EL } \\
\text { /Transcutol } \\
\text { HP }\end{array}$ & 3 & $\begin{array}{l}93.7 \pm \\
0.99\end{array}$ & $\begin{array}{l}7.58 \pm \\
0.53\end{array}$ & $\begin{array}{l}48.96 \\
\pm 3.44\end{array}$ & $\begin{array}{l}624.6 \\
\pm 23.75\end{array}$ & $\begin{array}{l}0.95 \\
\pm \\
0.024\end{array}$ & $\begin{array}{l}-29.1 \pm \\
1.78\end{array}$ & $\begin{array}{l}5.08 \\
\pm \\
0.25\end{array}$ & $116.53 \pm 11.7$ \\
\hline C5 & $\begin{array}{l}\text { GMS :0: } \\
\text { G } \\
70: 15: 15\end{array}$ & $\begin{array}{l}\text { Tween } \\
\text { 80/Transcutol } \\
\text { HP }\end{array}$ & 1.5 & $\begin{array}{l}99.7 \pm \\
0.78\end{array}$ & $\begin{array}{l}14.48 \\
\pm 0.49\end{array}$ & $\begin{array}{l}48.82 \\
\pm 1.63\end{array}$ & $\begin{array}{l}400.4 \\
\pm 33.87\end{array}$ & $\begin{array}{l}0.61 \\
\pm \\
0.075\end{array}$ & $\begin{array}{l}-31.9 \pm \\
1.33\end{array}$ & $\begin{array}{l}5.83 \\
\pm \\
0.08\end{array}$ & $119.40 \pm 4.91$ \\
\hline C6 & $\begin{array}{l}\text { GMS :0: } \\
\text { G } \\
70: 15: 15\end{array}$ & $\begin{array}{l}\text { Tween } \\
\text { 80/Transcutol } \\
\text { HP }\end{array}$ & 3 & $\begin{array}{l}92.2 \pm \\
9.03\end{array}$ & $\begin{array}{l}5.99 \pm \\
0.042\end{array}$ & $\begin{array}{l}38.91 \\
\pm 0.30\end{array}$ & $\begin{array}{l}772.3 \\
\pm 6.99\end{array}$ & $\begin{array}{l}0.54 \\
\pm \\
0.051\end{array}$ & $\begin{array}{l}-33.4 \pm \\
1.85\end{array}$ & $\begin{array}{l}5.93 \\
\pm \\
0.51\end{array}$ & $134.00 \pm 1.00$ \\
\hline $\mathrm{C7}$ & $\begin{array}{l}\text { GMS:0: } \\
\text { G } \\
70: 15: 15\end{array}$ & $\begin{array}{l}\text { Cremophor } \\
\text { EL/Transcutol } \\
\text { HP }\end{array}$ & 1.5 & $\begin{array}{l}99.3 \pm \\
0.33\end{array}$ & $\begin{array}{l}21.05 \\
\pm 0.35\end{array}$ & $\begin{array}{l}67.20 \\
\pm 5.98\end{array}$ & $\begin{array}{l}240.4 \\
\pm 22.87\end{array}$ & $\begin{array}{l}0.55 \\
\pm \\
0.012\end{array}$ & $\begin{array}{l}-19.2 \pm \\
0.47\end{array}$ & $\begin{array}{l}5.36 \\
\pm \\
0.36\end{array}$ & $135.96 \pm 12.10$ \\
\hline $\mathrm{C} 8$ & GMS:O: & $\begin{array}{l}\text { Cremophor EL } \\
\text { /Transcutol } \\
\text { HP }\end{array}$ & 3 & $\begin{array}{l}99.1 \pm \\
4.34\end{array}$ & $\begin{array}{l}9.09 \pm \\
1.27\end{array}$ & $\begin{array}{l}41.11 \\
\pm 0.92\end{array}$ & $\begin{array}{l}498.6 \\
\pm 47.01\end{array}$ & $\begin{array}{l}0.66 \\
\pm \\
0.014\end{array}$ & $\begin{array}{l}-29.2 \pm \\
0.81\end{array}$ & $\begin{array}{l}5.43 \\
\pm \\
0.47\end{array}$ & $166.40 \pm 5.09$ \\
\hline
\end{tabular}

*Total lipid conc. was $2 \% \mathrm{w} / \mathrm{v}$ and S/CoS conc. at ratio $3: 1$ was $3 \% \mathrm{w} / \mathrm{v}$ for all formulas.

* EE. Encapsulation efficiency, D.L. Drug loading, each value presents the mean of triplicate $(n=3) \pm$ S.D.

*SA : Stearic acid

*GMS: Glyceryl monostearate.

*Conc.: concentration

Table 5

Permeability parameters of different caffeine NLCs formulas (C3, C7 compared to market formula)

\begin{tabular}{|c|c|c|c|c|c|}
\hline $\begin{array}{l}\text { Formula } \\
\text { code }\end{array}$ & $\begin{array}{l}\text { Cumulative } \\
\text { Amounts of caffeine } \\
\text { permeated after } 24 \mathrm{~h} \\
\left(\mu \mathrm{g} / \mathrm{cm}^{2}\right) \pm \text { S.D }\end{array}$ & $\begin{array}{l}\text { Amount of caffeine accumulated in skin } \\
\text { per unit area }\left(\mu \mathrm{g} / \mathrm{cm}^{2}\right) \pm S . D\end{array}$ & $\begin{array}{l}\text { Drug flux } \\
J_{s s}\left(\mu g / \mathrm{cm}^{2} / h\right)\end{array}$ & $\begin{array}{l}\text { Permeation coefficient } \\
\mathrm{K}_{\mathrm{p}}\left(\mathrm{cm}^{2} / \mathrm{h}\right) \times 10^{-2}\end{array}$ & $\begin{array}{l}\text { Enhancement } \\
\text { ratio } \mathrm{E}_{\mathrm{r}}\end{array}$ \\
\hline market & $55.514 \pm 5.6$ & $1547.671 \pm 125.343$ & 2.2621 & 59.9 & - \\
\hline C3 & $150.832 \pm 2.149$ & $4830.472 \pm 41.461$ & 6.1375 & 165 & 2.713 \\
\hline $\mathrm{C7}$ & $87.2804 \pm 3.44$ & $4398.359 \pm 298.8837$ & 3.4979 & 94 & 1.546 \\
\hline
\end{tabular}


Table 6

Stability studies of the optimized formula (C3).

\begin{tabular}{|lll|}
\hline Parameters & \multicolumn{2}{l}{ C3 } \\
\cline { 2 - 3 } & Zero day & After 1 year* \\
\hline Color & White & White \\
\hline Clog formation & NO & NO \\
\hline Phase separation & NO & NO \\
\hline pH & $5.97 \pm 0.39$ & $5.5 \pm 0.12$ \\
\hline \% EE) & $72.55 \pm 0.12$ & $77.23 \pm 1.72$ \\
\hline Particle size (nm) & $358.6 \pm 1.45$ & $295.3 \pm 2.99$ \\
\hline PDI & 0.912 & 0.82 \\
\hline Zeta potential & $-24.8 \pm 0.70$ & $-23.7 \pm 0.160$ \\
\hline *refers to storage at $25^{\circ} \mathrm{C} /$ relative humidity $(\mathrm{RH}) 65 \%$. \\
\hline
\end{tabular}

\section{Figures}

\section{Temperature $\left({ }^{\circ} \mathrm{C}\right)$}

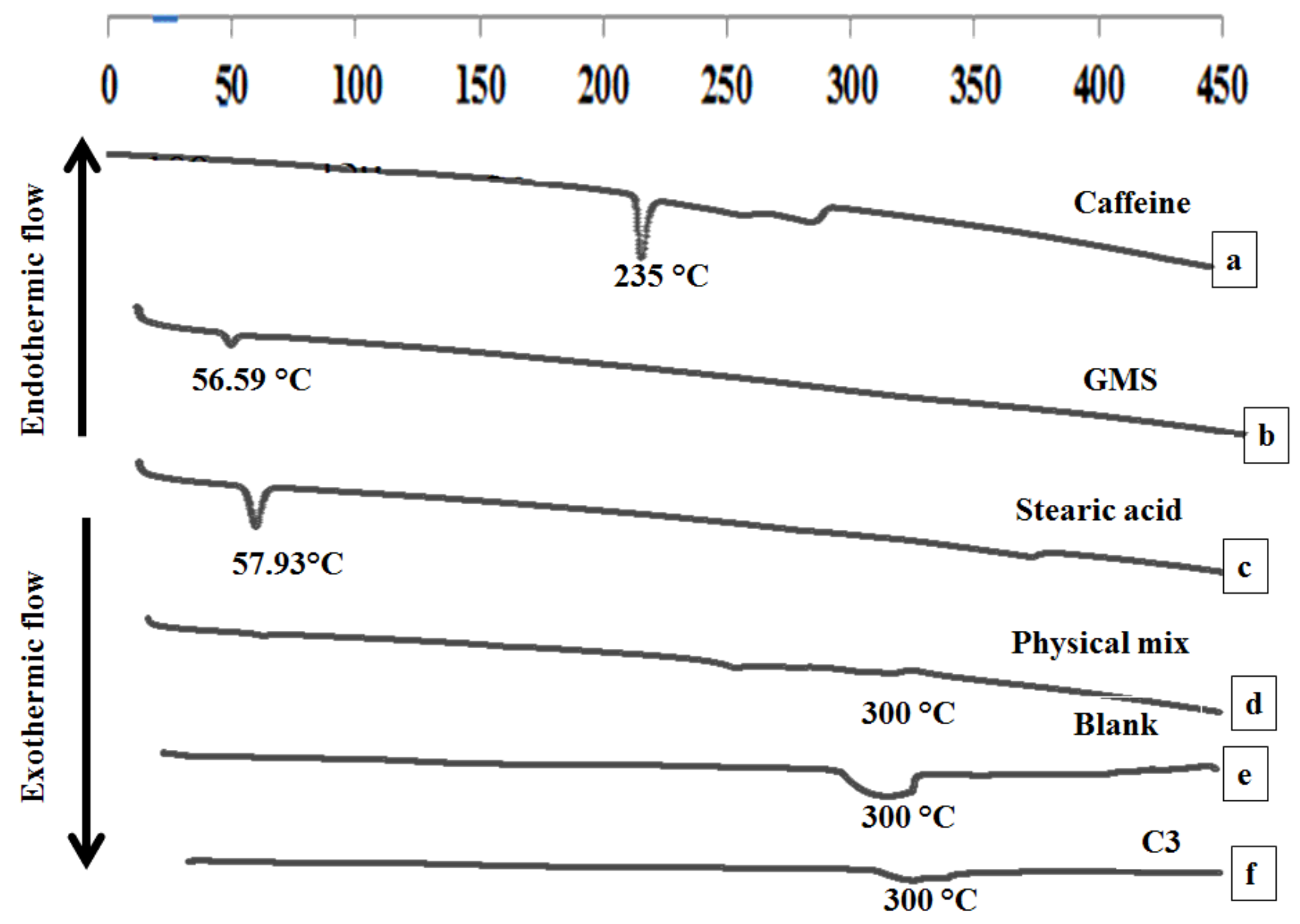

Figure 1

DSC thermogram of (a) caffeine; (b) GMS; (c) stearic acid; (d) physical mix; (e) blank NLC formula C3 and (f) Optimum NLC formula C3 


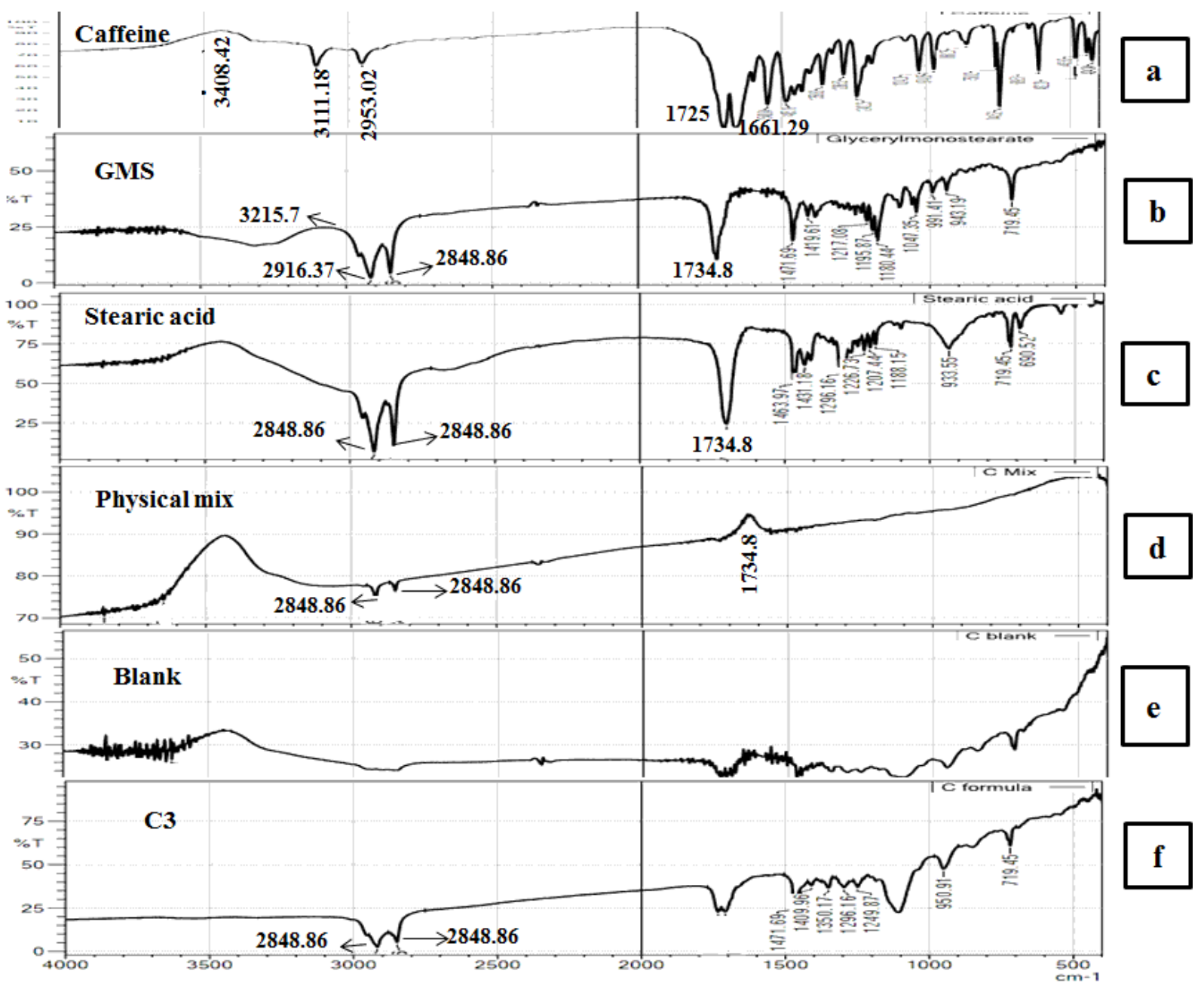

Figure 2

FTIR spectrum of (a) caffeine; (b) GMS; (c) stearic acid; (d) physical mix; (e) blank NLC formula C3 and (f) Optimum NLC formula C3 

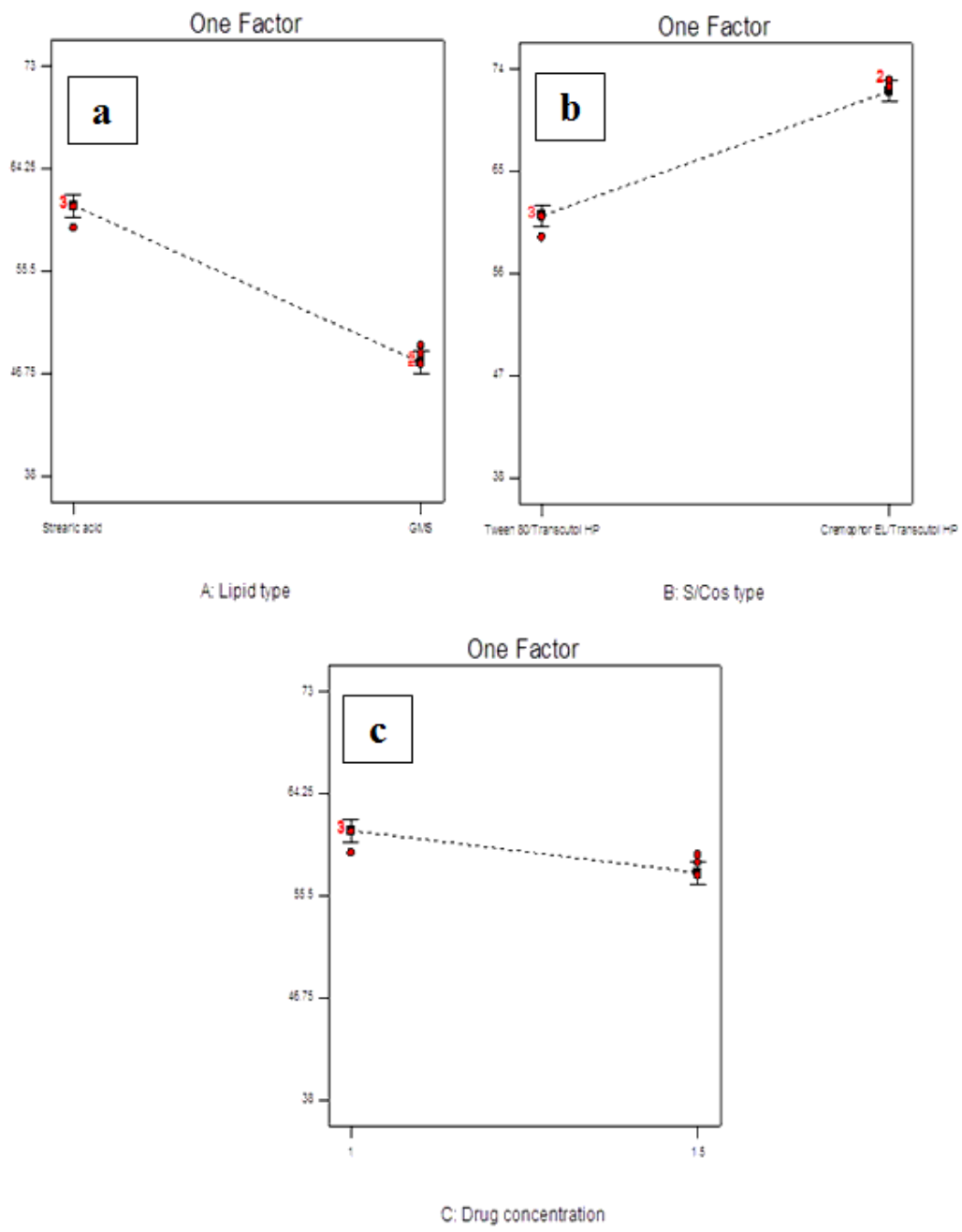

\section{Figure 3}

Main factor plot showing the effect of (a) lipid type, (b) surfactant type, (c) drug concentration on the \%EE of caffeine loaded NLCs 


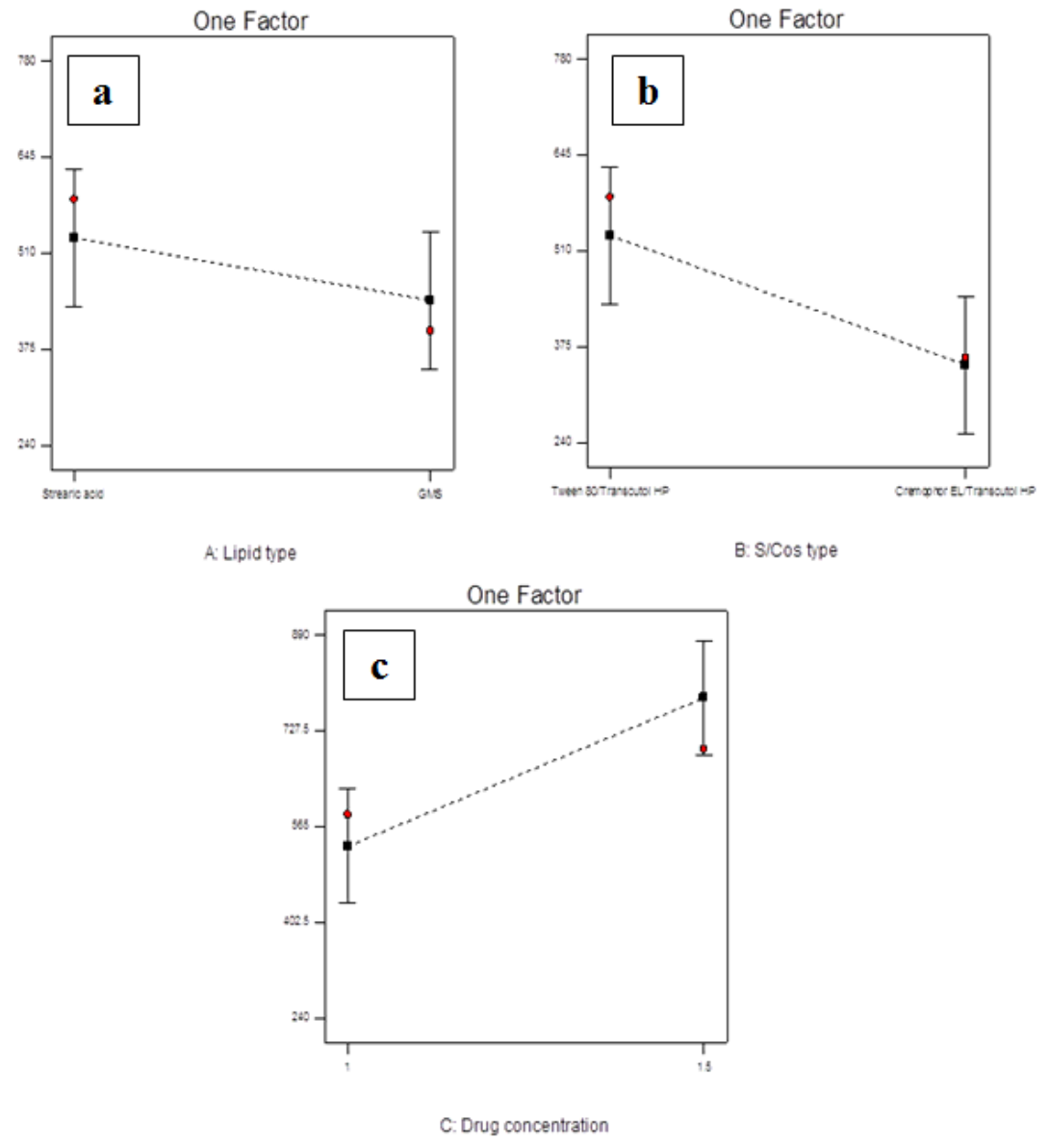

Figure 4

Main factor plot showing the effect of (a) lipid type, (b) surfactant type, (c) drug concentration on the particle size of caffeine loaded NLCs 


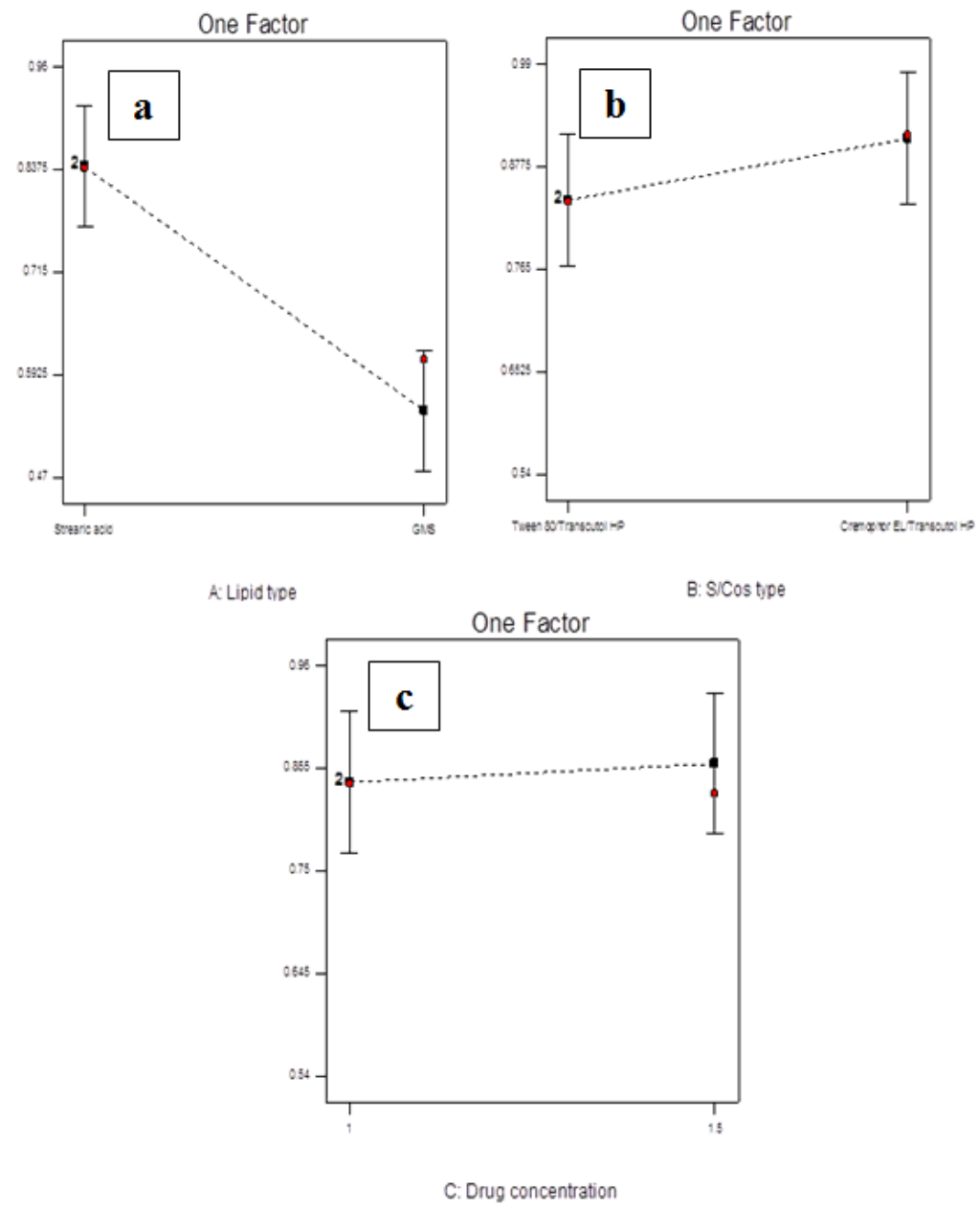

Figure 5

Main factor plot showing the effect of (a) lipid type, (b) surfactant type, (c) drug concentration on PDI of caffeine loaded NLCs

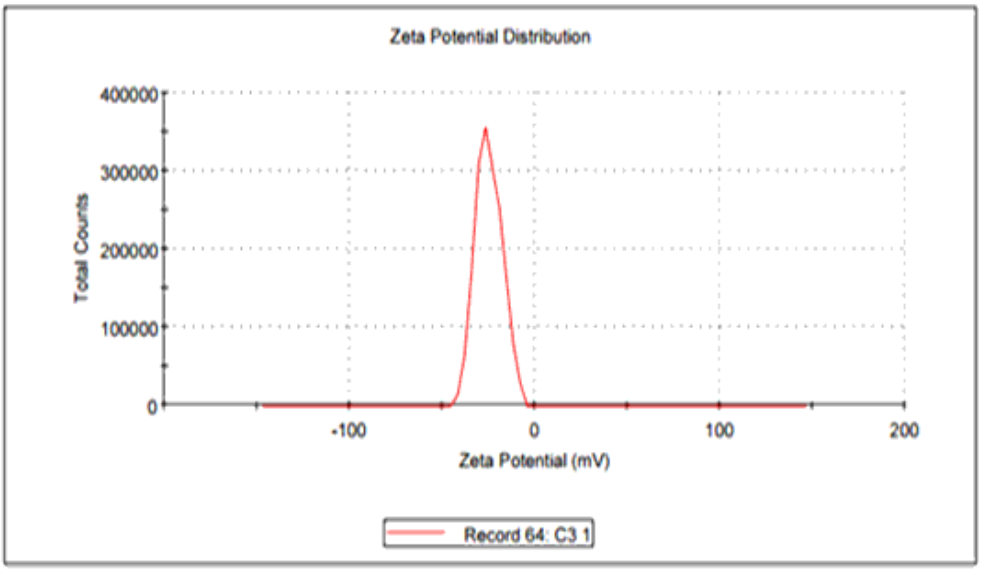

Figure 6

zeta potential of the optimized caffeine NLC formula (C3) 


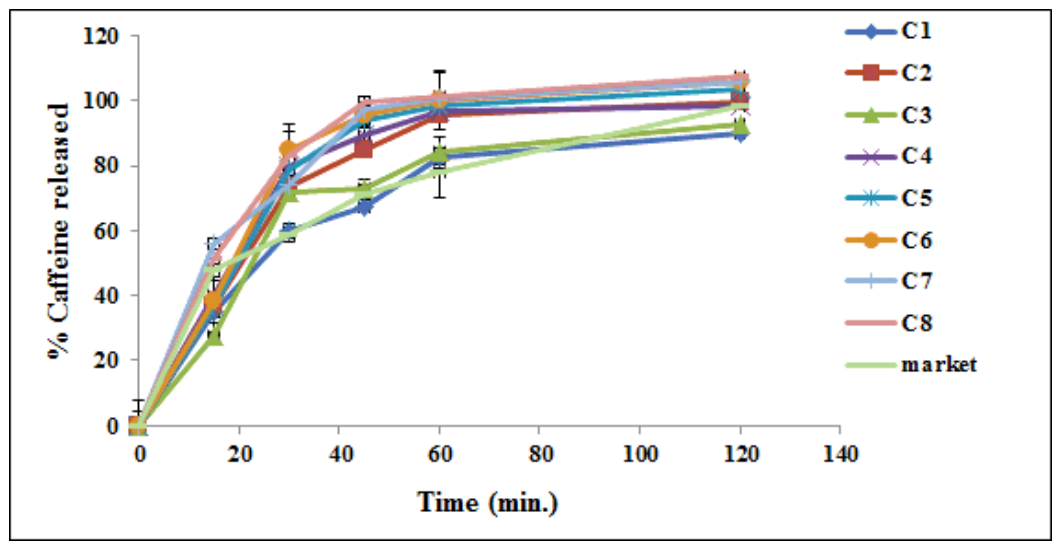

Figure 7

In-vitro release profile of drug loaded NLCs formulas (C1-C8) and their (market formula) in phosphate buffer at pH 7.4
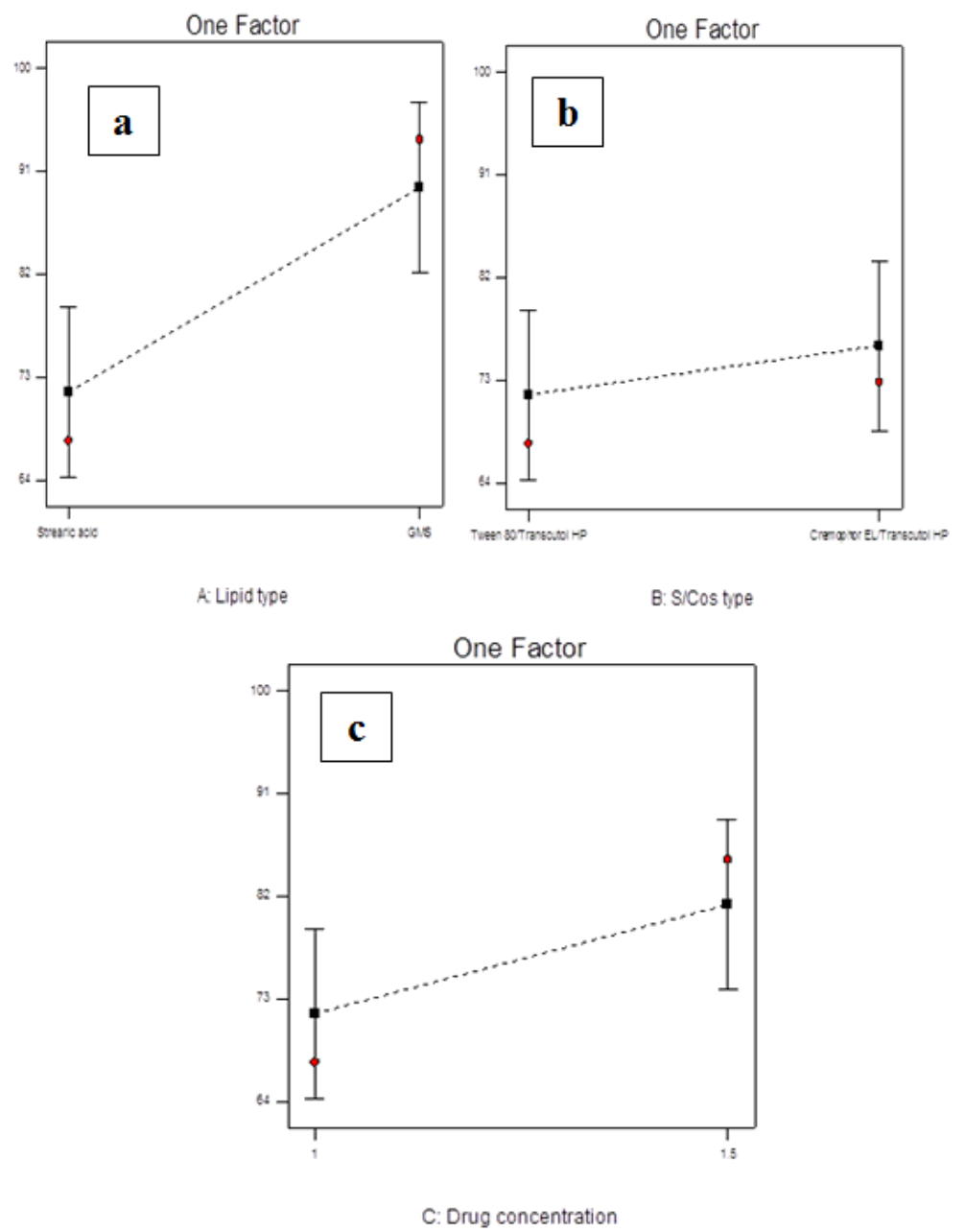

\section{Figure 8}

Main factor plot showing the effect of (a) lipid type, (b) surfactant type, (c) drug concentration on the \% release of caffeine loaded NLCs 


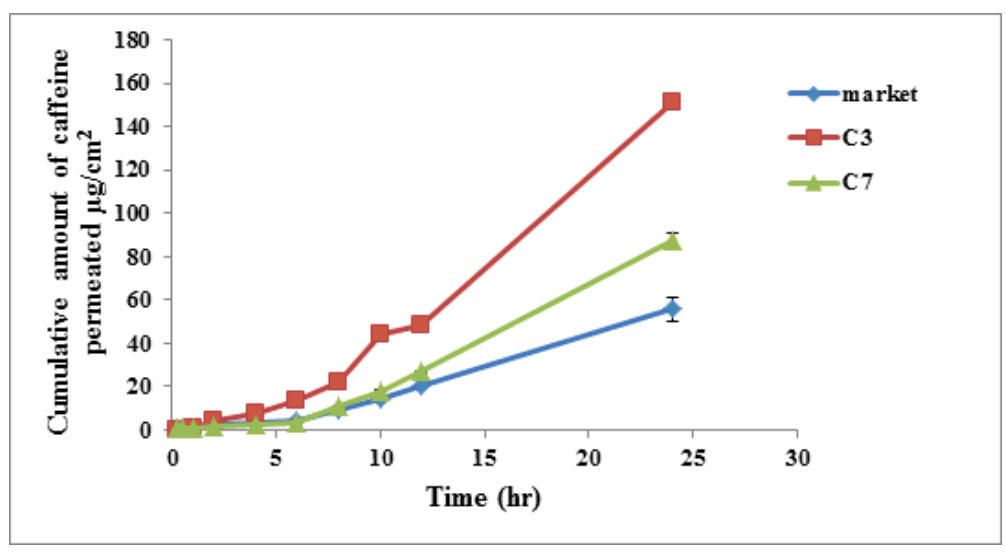

Figure 9

Ex-vivo permeation studies of caffeine NLCs formulas C3 and C7 compared to market formula

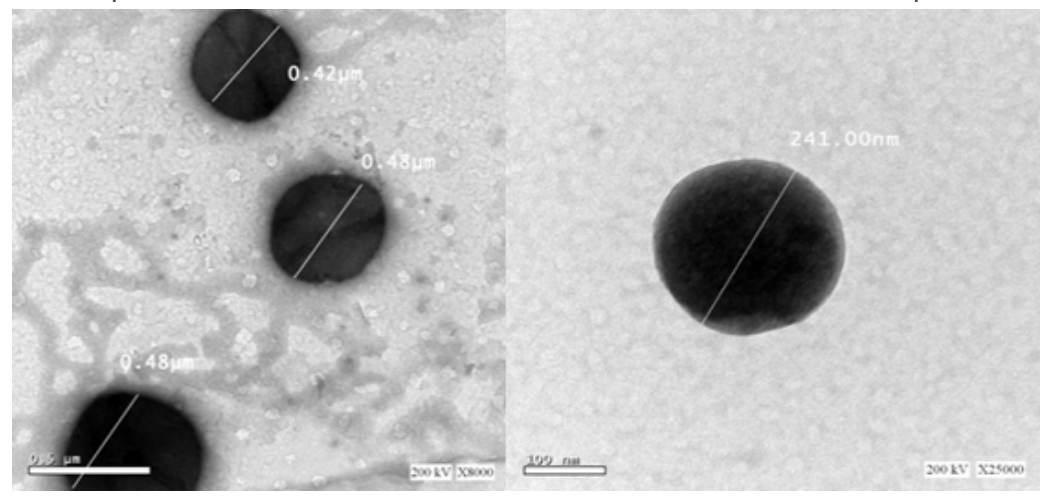

Figure 10

Transmission electron micrograph of optimum formula of caffeine loaded NLC (C3), (magnification $200 \mathrm{Kv}$; dilution 10 -fold with distilled water)

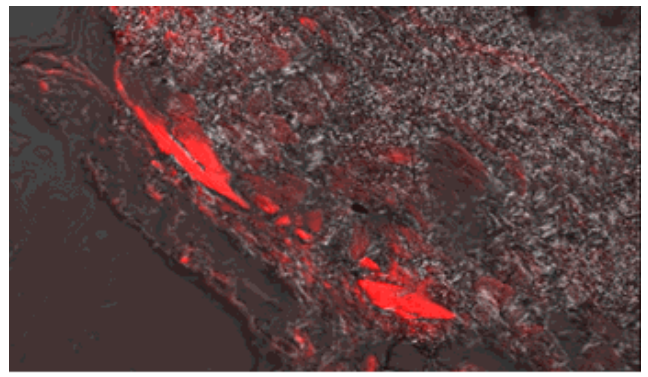

(a)

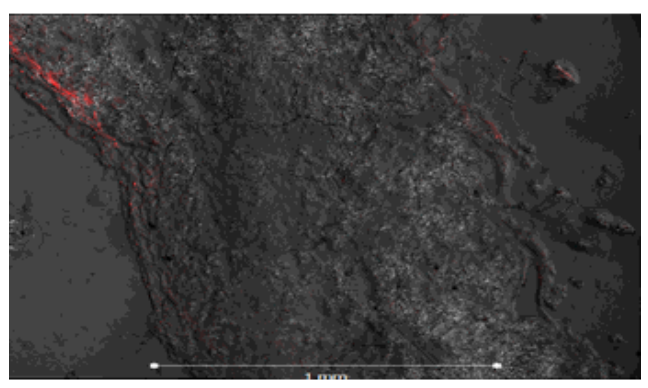

(b)

\section{Figure 11}

Confocal laser scanning microscopy (CLSM) images of vertical slices $(10 \mu \mathrm{m})$ of rat skin treated with (a) the optimized formula of caffeine-NLC (C3) NR loaded, overlay showed drug permeation through all skin layers, while (b) caffeine solution NR loaded (control) overlay showed drug accumulation within epidermal layer only 


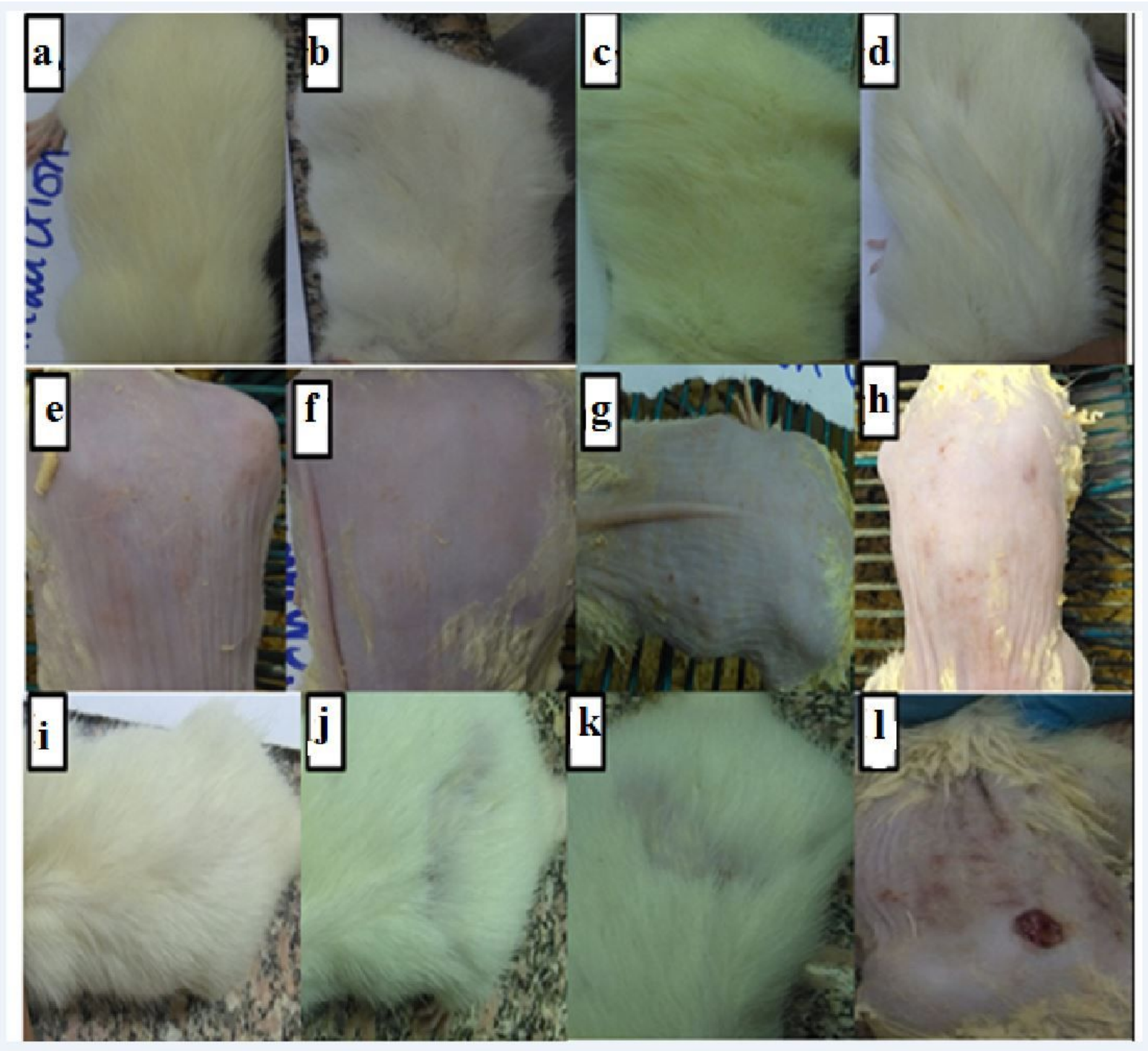

Figure 12

(a-d) showed the photographs of dorsal rats skin with thick hair taken at zero days before chemotherapeutic induction of rats in different groups in treated with; (a) the optimum formula C3, (b) blank formula, (c) market formula and (d) control. After chemotherapeutic induction with etoposide (1.5 $\mathrm{mg} / \mathrm{kg}$ ), once daily for three consecutive days, the rats showed bald skin without hairs, (e-h). After 30 days of treatment, (i-l), control group presented minimum hair growth while rat group treated with the formula C3 exhibited completely hair growth more than the market formula and the blank formula 


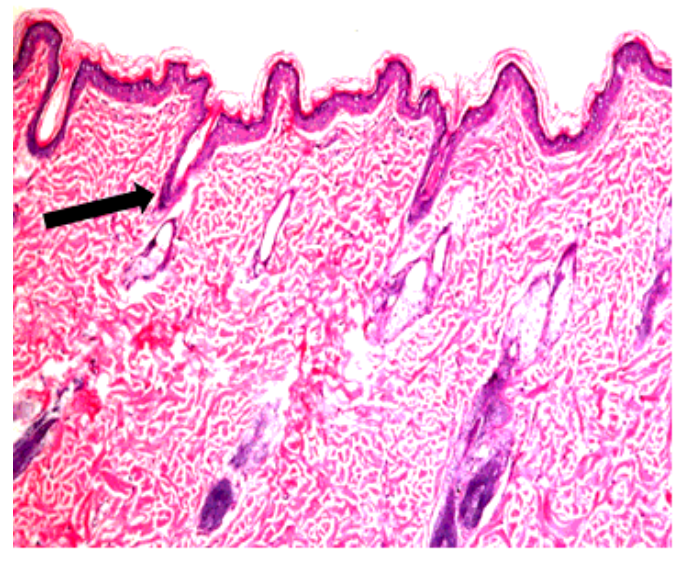

(a)

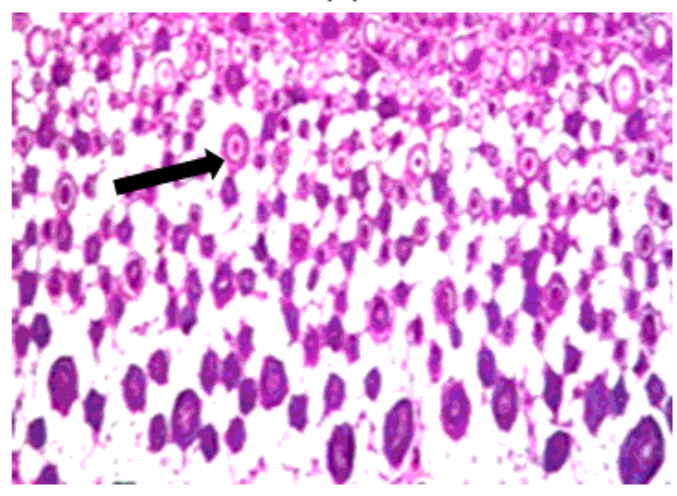

(c)

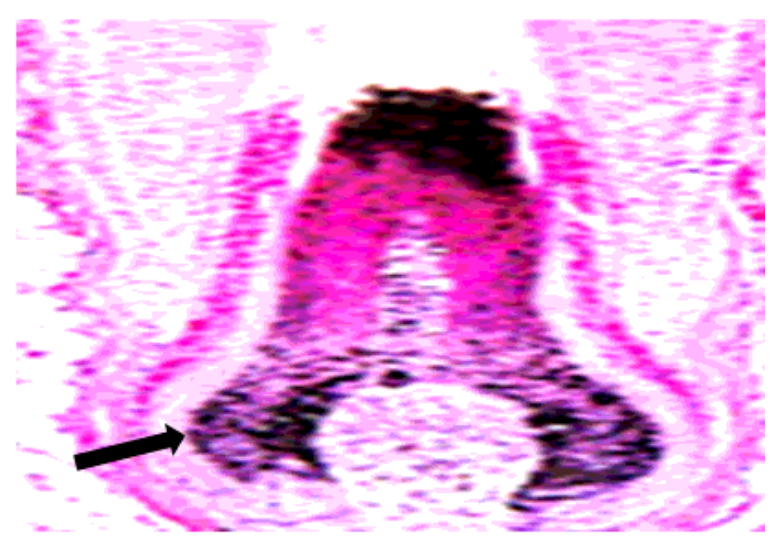

(b)

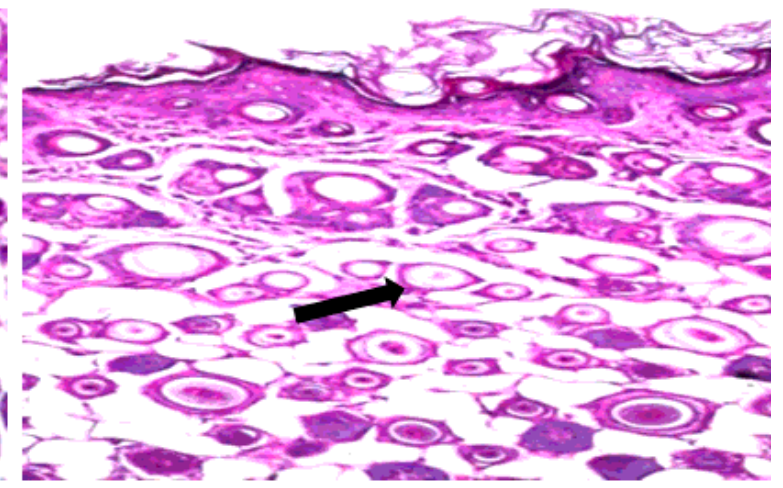

(d)

Figure 13

(a) showed the histopathological examination of the normal skin specimens, (b) showed hair follicle with spindle-like dermal papilla (DP), (c) showed the histological examination of skin specimens after chemotherapeutic induction, (d) hair follicles showed a ball-like small DP 


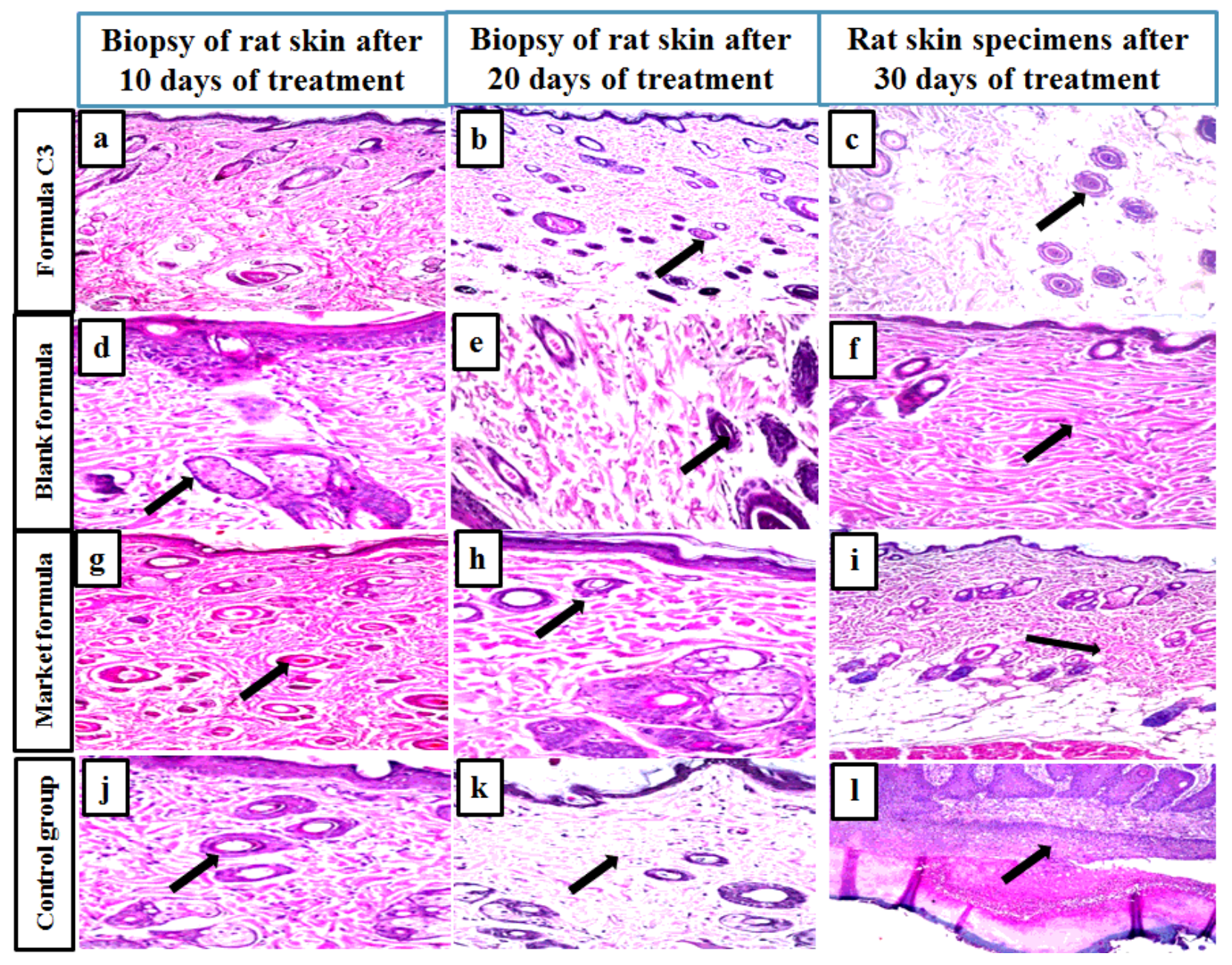

Figure 14

(a) Biopsy of skin rats treated with optimum formula (C3) after 10 days of treatment showed multiple follicles in dermis, (b) after 20 days of treatment, it showed mature and immature hair follicles (arrow), (c) after 30 days, it showed increased in the number of mature and immature hair follicles (arrow), (d) blank aminexil showed showed mild acanthosis in the epidermis after 10 days, (e) after 20 days, it showed multiple immature hair follicles and less mature ones (arrow), (f) after 30 days, mild epidermal acanthosis appeared (arrow), (g) market formula (A7) showed atrophy in most hair follicles (arrows) after 10 days of treatment, (h) after 20 days of treatment, it showed multiple hair follicles, (i) multiple mature hair follicles appeared after 30 days of treatment, (j) after 10 days, control group showed reduction and atrophy in the hair follicles (arrow), (k) after 20 days, it showed few immature hair follicles of the dermis, (I) after 30 days, control group showed showed focal necrosis, ulceration in the epidermis, and acanthosis

\section{Supplementary Files}

This is a list of supplementary files associated with this preprint. Click to download.

- GraphicalAbstract.jpg 